\title{
Worms: Education and Health Externalities in Kenya
}

\author{
Michael Kremer and Edward Miguel
}

Poverty Action Lab Paper No. 6

September 2001

(c) Copyright 2003 Michael Kremer and Edward Miguel

Poverty Action Lab

TRANSLATING RESEARCH INTO ACTION 


\begin{abstract}
Intestinal helminths - including hookworm, roundwom, schistosomiasis, and whipworm - infect more than one-quarter of the world's population. A randomized evaluation of a project in Kenya suggests that school-based mass treatment with deworming drugs reduced school absenteeism in treatment schools byone quarter; gains are especially large among the youngest children. Deworming is found to be cheaper than alternative ways of boosting school participation. By reducing disease transmission, deworming creates substantial extemality health and school participation benefits among untreated children in the treatment schools and among children in neighboring schools. These externalities are large enough to justify fully subsidizing treatment. We do not find evidence that deworming improves academic test scores. Existing experimental studies, in which treatment is randomized among individuals in the same school, find small and insignificant deworming treatment effects on education; however, these studies underestimate true treatment effects if deworming creates positive externalities for the control group and reduces treatment group attrition.
\end{abstract}

Edward Miguel

Department of Economics

University of California at Berkeley

emiguel@econ.berkeley.edu
Michael Kremer

Department of Economics

Harvard University

and NBER

mkremer@fas.harvard.edu 


\section{Introduction}

Hookworm, roundworm, whipworm, and schistosomiasis infect more than one in four people worldwide and are particularly prevalent among school-age children in developing countries. We examine the impact of an inexpensive school-based deworming program in rural Kenya. The order in which the seventy-five primary schools in the sample were phased into the deworming project was randomized, which allows us to plausibly identify the impact of the health program.

While an older retrospective literature suggests that worms may have a negative impact on education, more recent experimental studies present inconclusive evidence regarding the impact of deworming treatment on education (Dickson et al. 2000). These studies typically randomize treatment among children within the same school and then compare cognitive ability among those treatment and comparison pupils who attend a later testing session. However, these studies suffer from several important methodological problems. To the extent that deworming reduces the transmission of disease to the comparison pupils, these studies both underestimate the effects of treatment on the treated and fail to account for the externalities that many economists would argue provide a key rationale for government deworming subsidies. Moreover, existing studies typically do not consider school participation as an outcome, and they fail to correct for the sample attrition bias that results if deworming affects school participation.

We examine a program that randomized deworming treatment at the school level. We find that deworming led to significantly higher primary school participation after two years of medical treatment. Among the treatment group, the absenteeism rate fell by approximately one-quarter, or seven percentage points. This effect is larger than would be suggested by retrospective estimates of the effect of worms on school participation. School participation gains were especially large among the youngest children.

We also find that deworming creates large externality benefits - significant reductions in worm burdens and higher school participation - by reducing the local transmission of helminth larvae. These externality benefits were enjoyed by both untreated children in treatment schools and children in neighboring primary schools. Failure to take these externalities into account leads to substantially 
underestimating the cost effectiveness of treatment. Including the externality benefits of treatment, the cost per additional year of school participation is $\$ 3$, considerably less than the cost of alternative methods of increasing school participation. Moreover, internalizing these externalities would likely require not only fully subsidizing deworming, but actually paying people to receive treatment.

We do not find any evidence that deworming increased test scores. However, the school participation gains we observe are not large enough to generate statistically significant test score gains given the observed cross-sectional relationship between school attendance and test scores.

The current study contributes to the broader debate on the role of health in education and economic development. Many observers of economic development have asserted that poor health and nutrition play a central role in underdevelopment (Das Gupta 1993, Fogel 1994), and Bloom and Sachs (1998) use cross-country data to argue that this is particularly true for Africa, the region with the most severe tropical disease burden. ${ }^{1}$ One potential channel is the impact of poor health on education, yet given the limited experimental evidence and the difficulty of inferring causality from correlations in nonexperimental data, some remain sceptical (see Behrman's 1996 literature review). ${ }^{2}$ The results of the current study raise the possibility that the cross-country relationship between tropical disease and income could in part be caused by the negative impact of poor child health on educational attainment in less developed countries, which later translates into lower adult income. The results also have potential implications for public health policy in countries with substantial tropical disease burdens. The World Health Organization (WHO) (1999) reports that nearly half of the total disease burden in Africa is due to

\footnotetext{
${ }^{1}$ Helminth infections in particular have long been seen as impeding economic development. The British Colonial Kenya Native Affairs Department Annual Report 1927 writes, "The most prevalent diseases in the Kavirondo districts (which include present-day Busia district) are respiratory complaints, worms, malaria, and ulcers," and regarding central Kenya, the report states, "a very high rate of helminth infection, estimated to be as high as 78 percent, exists ... and a great deal of the idleness and lethargy among the natives may be attributable to this cause" (Colony and Protectorate of Kenya 1928). Helminth infections also once constituted a major public health problem in the U.S. South, where a random sample of residents tested by the Rockefeller Sanitary Commission between 1909 and 1914 revealed that over 40 percent were infected with hookworm (Brinkley 1994). Garland Brinkley argues that approximately one-half of the increase in agricultural productivity in the U.S. South between 1910 and 1920 can be attributed to reductions in hookworm prevalence associated with the Rockefeller Foundation's campaign against the disease.

${ }^{2}$ One exception is anemia; several prospective studies suggest iron supplementation improves academic outcomes (Nokes et al. 1998). For an alternative view of the links between health, nutrition, and economic development, see Strauss and Thomas (1998).
} 
infectious and parasitic diseases, including helminth infections. To the extent that these infectious diseases are characterized by treatment externalities similar to those estimated for deworming in this study, extensive government subsidies for the treatment of infectious diseases would be optimal.

The paper is organized as follows: Section 2 reviews the existing literature on helminths and education. Section 3 describes the project we evaluate in rural Kenya and presents the baseline educational and medical characteristics. Section 4 describes the estimation strategy. Sections 5, 6, and 7 discuss the program's effect on health, school participation, and test scores, respectively. Section 8 examines the cost-effectiveness of deworming relative to other ways of improving health and boosting school participation and then considers what subsidies for deworming would be optimal given the externalities involved. The final section summarizes and discusses implications of the results.

\section{Intestinal Helminth (Worm) Infections}

\subsection{Background on Intestinal Helminth Infections}

Recent studies estimate that 1.3 billion people worldwide are infected with roundworm (Ascaris lumbricoides), 1.3 billion with hookworm (Necator americanus, Ancylostoma duodenale), 900 million with whipworm (Trichuris trichura), and 200 million with schistosomiasis. Infection rates are particularly high among school-age children and in Sub-Saharan Africa (Bundy, et al. 1998; WHO 1993).

The geohelminths (hookworm, roundworm, and whipworm) are transmitted through contact with or ingestion of infected fecal matter. This can occur, for example, if children do not have access to a latrine and instead defecate in the fields near their home or school, areas where they also play. Schistosomiasis is acquired through contact with infected freshwater streams and lakes. For example, people in the area of Kenya where the project took place often walk to nearby Lake Victoria to bathe, fish, or swim. School-age children often exhibit greater prevalence of geohelminth infection and higher infection intensity than adults, as well as the highest disease burden (since morbidity is related to infection intensity), due to a combination of high exposure and immunological factors (Bundy 1988). 
Since helminths do not reproduce within the human host, high worm burdens are the result of frequent infection and re-infection.

The distribution of worm burden is typically highly skewed: the majority of infected individuals have light infections, while a minority are heavily infected. While children with light helminth infections may be asymptomatic, more severe worm infections can lead to iron deficiency anemia, protein energy malnutrition, stunting (a measure of chronic undernutrition), wasting (a measure of acute undernutrition), listlessness and abdominal pain. ${ }^{3}$ Schistosomiasis often has more severe clinical consequences than the geohelminth infections, including hepatosplenomegaly (enlargement of the liver and spleen), and may be fatal in a small fraction of cases.

Intestinal helminths are treated using low-cost single-dose oral therapies (Bundy and Guyatt 1996). The World Bank, World Health Organization, UNESCO, and UNICEF have endorsed mass school-based deworming programs in areas with helminth infection prevalence over fifty percent, since mass treatment eliminates the need for costly individual parasitological screening (Warren et al. 1993; World Bank 1993; WHO 1987). Albendazole is used to treat the geohelminths, and praziquantel is used to treat schistosomiasis. Since reinfection is common, albendazole is taken twice per year and praziquantel is taken once per year. Medical treatment with albendazole and praziquantel delivered through a large-scale mass treatment program may cost as little as 49 cents per person per year (Partnership for Child Development 1999). These drugs have been endorsed as highly effective by scientific committees of the World Health Organization, although single-dose albendazole treatments are often only moderately effective against severe whipworm infections (Bennett and Guyatt 2000). The drugs sometimes have minor side effects, including stomach ache, diarrhea, dizziness, and vomiting in some cases (WHO 1992). However, there is concern about the possibility that albendazole could cause

\footnotetext{
${ }^{3}$ Refer to Adams et al. (1994), Corbett et al. (1992), Hotez and Pritchard (1995), and Pollitt (1990). If left untreated, geohelminth infections may have more serious medical consequences in a minority of cases: roundworm infections sometimes lead to fatal intestinal obstruction, hookworm infection can cause severe anemia, and whipworm is associated with chronic dysentery.
} 
birth defects (WHO 1992, Cowden and Hotez 2000), and for this reason standard practice is not to treat girls of reproductive age in mass deworming programs (Bundy and Guyatt 1996).

Epidemiologists have hypothesized that medical treatment for helminth infections creates externality benefits for other community members by reducing worm deposition in the community and thus limiting re-infection among other community members (Anderson and May 1991). The limited existing empirical evidence suggests that these externalities may in fact be substantial. For example, adult worm burden fell by nearly fifty percent in communities where school children were mass treated for worms on the island of Montserrat (Bundy et al. 1990). In the absence of frequent re-infection, worm burdens fall rapidly given the relatively short average life spans of intestinal worms: twelve months for roundworm and whipworm, two years for hookworm, and three years for schistosomiasis mansoni (Bundy and Cooper 1989; Anderson and May 1991). ${ }^{4}$

\subsection{Evidence on Worms and Education}

The educational impact of deworming is often taken as a key issue in assessing the priority the poorest countries should accord to deworming (Dickson et al. 2000). Moreover, wide adoption of schoolbased helminth control programs will likely require the active participation of education ministries in developing countries, and this may require evidence on the impact of deworming on education.

It has been hypothesized that intense worm infections may reduce educational achievement (Bundy 1994; Drake et al. 1999; Stoltzfus et al. 1997). This seems plausible, since worms can cause anemia and a number of prospective studies suggest that iron supplementation improves the educational outcomes of anemic schoolchildren (Nokes et al. 1998). Other channels through which worms might affect learning have also been proposed, including protein-energy malnutrition. However, the evidence from recent experimental studies examining the impact of deworming on cognition and education is inconclusive (Drake et al. 1999; Watkins and Pollitt 1997). In a review of these studies published in the

\footnotetext{
${ }^{4}$ Maximum lifespans are considerably longer, but average lifespan is the key factor in epidemiological modelling (Anderson and May 1991).
} 
prestigious British Medical Journal, Dickson et al. (2000) claim that "the evidence of benefit for mass [deworming] treatment of children related to positive effects on [physical] growth and cognitive performance is not convincing. In light of these data, we would be unwilling to recommend that countries or regions invest in programmes that routinely treat children with anthelmintic drugs."

The existing randomized evaluations on worms and education, on which Dickson et al. (2000) base their conclusions, suffer from several important shortcomings. First, existing studies randomize the provision of deworming treatment within schools to treatment and placebo groups, and then examine the impact of deworming on cognitive outcomes. However, the difference in educational outcomes between the treatment and placebo groups understates the actual impact of deworming if placebo group pupils also experience health gains due to positive local deworming externalities. The within-school randomization design of existing studies is also unable to estimate the externality benefits to treatment.

Second, the existing randomized studies focus principally on cognitive performance (such as tests of recall) rather than outcomes of more direct interest to economists and policymakers - school attendance, enrollment, promotion, test scores, and ultimately, labor market outcomes. Of the existing randomized studies, two find that deworming is associated with improved test performance among either heavily infected pupils or wasted pupils (Nokes et al. 1992; Simeon, Grantham-McGregor, Callender, and Wong 1995), two others find insignificant test score treatment effects (Simeon, Grantham-McGregor, and Wong 1995; Watkins et al. 1996a, 1996b), and one finds significant negative deworming treatment effects (Pollitt et al. 1991). Due to their limited durations - the longest existing randomized study tracks outcomes for less than one school year - none of these studies estimate effects on grade promotion rates.

Only two of the existing randomized studies examine deworming treatment effects on school attendance, and both were based on attendance registers, which are notoriously inaccurate in many developing countries. Simeon, Grantham-McGregor, Callender, and Wong (1995) examine growthstunted Jamaican children with heavy whipworm infections who received albendazole. These children had 9.9 percentage points higher school attendance in the six months following deworming treatment (as recorded in school registers) than comparable children who did not receive treatment. As average 
attendance was 68 percent, this constituted a reduction of over one-third in total pupil absenteeism. However, this result should perhaps be interpreted with caution since thirty-five percent of the pupils in the sample were missing attendance register data.

On the other hand, a study of Guatemalan children with roundworm and whipworm infections found no gain in primary school attendance (as recorded in teachers' attendance books) in the six months following treatment with albendazole (Watkins et al. 1996a, 1996b). However, the authors only consider months in which pupils were "actively enrolled" in school; periods in which pupils were temporarily not in school were dropped from the sample. This is a form of attrition bias which may explain the high rates of measured attendance in Guatemala, 90 percent. To the extent that treated pupils were healthier and had fewer inactive periods, these estimates understate the true impact of deworming on school attendance. ${ }^{5}$

Finally, since most existing studies fail to measure school participation, and none does so adequately, they are unable to address sample attrition bias. This is likely to be an important estimation issue to the extent that deworming leads to large improvements in school participation, as suggested by our results and those in Jamaica. For example, in Nokes et al. (1992), there are test score data for 41 of the 70 pupils initially assigned to the placebo group and for 62 of the 70 pupils assigned to the treatment group; however, no attempt is made to explain the causes of differential attrition, nor to correct or place bounds on the resulting treatment effect estimates. To the extent that initially poor academic performers were more likely to remain in the sample in treatment schools due to health gains, the test score estimates in Nokes et al. understate actual treatment effects. Despite this possible bias, Nokes et al. estimate a positive impact of deworming on test performance. The possibility of attrition bias is not addressed in Simeon, Grantham-McGregor, Callender, and Wong (1995), Simeon, Grantham-McGregor, and Wong (1995), or Pollitt et al. (1991).

\footnotetext{
${ }^{5}$ Medical anthropological evidence from a nearby region of western Kenya suggests that helminth infections reduce school attendance (Geissler et al. 2000). Geissler et al. conducted weekly interviews over the course of seven months with a random sample of 57 school children aged eleven to seventeen years, and found that on 12 percent of all days children complained of abdominal pains which, he argues, are overwhelmingly due to intestinal helminth infections. In 44 percent of these abdominal pain episodes - or five percent of all interviews - the child claimed that she did not attend school due to these abdominal problems, accounting for one quarter of total school absenteeism in
} 


\section{The Primary School Deworming Project in Busia, Kenya}

We evaluate the Primary School Deworming Project (PSDP), which was carried out by a Dutch non-profit organization, Internationaal Christelijk Steunfonds Africa (ICS), in cooperation with the Busia District Ministry of Health office. The project took place in Budalangi and Funyula divisions of southern Busia district, a poor and densely-settled farming region in western Kenya adjacent to Lake Victoria. Parasitological surveys conducted by the Kenyan Ministry of Health and ICS indicate that these two divisions have the highest infection rates in Busia district. The 75 project schools consist of nearly all rural primary schools in this area, and in total, over 30,000 pupils between the ages of six and eighteen are enrolled in these schools.

Table 1 presents the project timeline. In January 1998, the seventy-five PSDP schools were randomly divided into three groups (Group 1, Group 2, and Group 3) of twenty-five schools each: the schools were first stratified by administrative sub-unit (zone) and by their involvement in other nongovernmental assistance programs, ${ }^{6}$ were then listed alphabetically, and every third school was then assigned to a given project group. Due to ICS's administrative and financial constraints, the health intervention was phased in over several years. Group 1 schools received free deworming treatment in both 1998 and 1999, Group 2 schools in 1999, and Group 3 began receiving medical treatment in 2001. This project design implies that in 1998, Group 1 schools were treatment schools, while Group 2 and Group 3 schools were the comparison schools; in 1999, Group 1 and Group 2 schools were the treatment schools and Group 3 schools were comparison schools. Figure 1 shows the approximate location of the three groups of schools based on global positioning system (GPS) data. ${ }^{7}$

the sample. Geissler et al. did not record whether children with more intense worm infections were more likely to drop out. Refer to Geissler (1998a, 1998b) for further anthropological research on worms in western Kenya.

${ }^{6}$ Twenty-seven of the seventy-five project schools were also involved in other NGO projects, which consisted of financial assistance for textbook purchase and classroom construction, as well as teacher performance incentives. ${ }^{7}$ The GPS data used throughout the paper were collected before May 2000 (when the U.S. stopped intentionally downgrading GPS accuracy), and so may only be accurate to within several hundred meters, thus one school in Figure 1 appears to be in Uganda. The school that appears to be in Lake Victoria is actually on a small island. 


\subsection{Baseline Characteristics}

The ICS field staff administered questionnaires in early 1998 and again in early 1999 to collect information on school and pupil characteristics. Table 2 indicates that prior to treatment, the groups were similar on most demographic, nutritional, and socioeconomic characteristics, but that despite randomized assignment - which produces groups with similar characteristics in expectation - Group 1 pupils appear to be somewhat worse off than Group 2 and 3 pupils along some dimensions, potentially creating a bias against finding significant program effects. There are no statistically significant differences across the Group 1, Group 2, and Group 3 schools in enrollment, distance to Lake Victoria, school sanitation facilities, the local density of other primary schools, or pupils' weight-for-age, self-reported health problems, or asset ownership. Pupils' rates of helminth infections in the surrounding geographic zone are also nearly identical across the three groups. However, Group 1 pupils had statistically significantly more (self-reported) blood in stool, a symptom of schistosomiasis infection, and were not as clean as Group 2 and Group 3 pupils (as observed by NGO field workers). Group 1 schools also had substantially lower average scores on 1996 Kenya government primary school academic examinations than both Group 2 and Group 3 schools, although the difference is not significant at traditional confidence levels. Pre-treatment school average test scores are included as explanatory variables in most empirical specifications to control for pre-program variation in average school academic quality.

In January and February 1998, a random sample of ninety grade three to eight pupils (fifteen per grade) in each of the 25 Group 1 schools were selected to participate in a parasitological survey conducted by the Kenya Ministry of Health, Division of Vector Borne Diseases. ${ }^{8}$ Individual worm burden is proxied with the density of worm larvae in stool, although this is thought to be an imperfect measure of the actual number of helminth infections (Medley and Anderson 1985).

\footnotetext{
${ }^{8}$ Each child in the parasitological sample was given a plastic container and asked to provide a stool sample; samples were examined in duplicate within twenty-four hours using the Kato-Katz method to determine helminth infection prevalence and intensity. Group 2 and Group 3 schools were not included in the 1998 parasitological survey, since it was not considered ethical to collect detailed health information from pupils who were not scheduled to receive medical treatment in that year.
} 
Table 3 presents the parasitological survey results, which indicate that 92 percent of pupils had at least one helminth infection and nearly 37 percent had at least one moderate-to-heavy helminth infection using modified WHO infection intensity standards described in Brooker et al. (2000b). ${ }^{9}$ The figures in Table 3 are likely to understate actual infection prevalence and intensity if the most heavily infected children were more likely to be absent from school on the day of the survey. Moderate-to-heavy worm infections are more likely among younger pupils, boys, and pupils with few assets at home - especially latrines (results not shown). The importance of latrine ownership is consistent with the fact that intestinal helminths are transmitted through fecal matter. As expected, pupils who attend schools near Lake Victoria have substantially higher rates of schistosomiasis infection. Although helminth prevalence in western Kenya is reasonably high by international standards, there are many other African settings with similar infection profiles (Brooker et al. 2000a).

\subsection{The Intervention}

Following the recommendations of the World Health Organization (WHO 1992), all schools with geohelminth (hookworm, roundworm, and whipworm) prevalence over 50 percent were mass treated with albendazole every six months. All schools with schistosomiasis prevalence over 30 percent were mass treated with praziquantel once per year. ${ }^{10}$ All treatment schools met the geohelminth cut-off in both 1998 and 1999 and were mass treated with albendazole. Six of 25 treatment schools met the schistosomiasis cut-off in 1998 and sixteen of fifty treatment schools met the cut-off in 1999, and these schools received

\footnotetext{
${ }^{9}$ The moderate infection thresholds are: 250 epg for S. mansoni, and 5,000 epg for Roundworm, both the WHO standard, and 750 epg for Hookworm and 400 epg for Whipworm, both somewhat lower than the WHO standard. ${ }^{10}$ The medical protocol was designed in collaboration with the Partnership for Child Development, and was approved by the Ethics Committee of the Kenya Ministry of Health and the Busia District Medical Officer of Health. The 30 percent threshold for mass praziquantel treatment is less than the WHO standard of 50 percent, although in practice only a handful of schools had schistosomiasis prevalence between 30 to 50 percent. Pupils in the parasitological sub-sample who were found to be infected, but who attended schools that did not qualify for mass treatment with praziquantel, were individually treated for schistosomiasis.
} 
mass treatment with praziquantel. ${ }^{11}$ Medical treatment was delivered to the schools by Kenya Ministry of Health public health nurses, as well as ICS public health officers.

Following standard practice (Bundy and Guyatt 1996), under the medical protocol for this study, girls thirteen years of age and older were not to be treated due to concerns about the potential teratogenicity of the drugs (WHO 1992). Pregnancy test reagent strips require trained staff to administer and are not practical during mass treatment (Bundy and Guyatt 1996). Personal interviews (i.e., asking girls when they had their most recent menstrual period) may not be effective in determining pregnancy status in this setting because pregnant girls might conceal such information from the interviewer, fearing that the information might not be held in confidence. Pregnant girls are often expelled from Kenyan primary schools (although this is not official government policy).

In addition to medical treatment with albendazole and praziquantel, the treatment schools received education on worm prevention behaviors - including washing hands before meals, wearing shoes, and not swimming in the lake - through regular public health lectures, the training of one teacher in each treatment school on worm prevention education, and the provision of worm prevention wall charts.

ICS obtained community consent in all treatment schools in 1998. A series of community and parent meetings were held in treatment schools, at which the project was described and parents who did not want their child to participate in the project were asked to inform the school headmaster. Under the recommendation of the Kenya Ministry of Health, beginning in January 1999 ICS required signed parental consent for all children to receive medical treatment; consent typically took the form of parents signing their name in a notebook kept at school by the headmaster. This is not a trivial requirement for many households: travelling to school to sign the book may be time-consuming, and some parents may be

\footnotetext{
${ }^{11}$ In 1998, pupils received $600 \mathrm{mg}$ albendazole doses during each round of treatment, following the protocol of an earlier Government of Kenya Ministry of Health deworming project in Kwale, Kenya. In 1999, pupils were treated with $400 \mathrm{mg}$ albendazole (WHO [1992]). Praziquantel was provided at approximately $40 \mathrm{mg} / \mathrm{kg}$ (WHO1992) in both 1998 and 1999. The NGO used generic drugs in 1998 and non-generic drugs - SmithKline Beecham's Zentel (albendazole) and Bayer's Biltricide (praziquantel) - in 1999.
} 
reluctant to meet the headmaster when they are behind on school fees - a common problem in these schools.

\subsection{Compliance with Medical Treatment}

Table 4 presents medical compliance information, and indicates that 78 percent of those pupils scheduled to receive treatment (i.e., girls under thirteen years old and all boys in treatment schools) received at least some medical treatment through the program in 1998. Absence from school on the day of drug administration was the recorded cause of non-compliance in the majority of cases. Nineteen percent of girls thirteen years of age or older also received medical treatment in 1998, which was partly because of confusion in the field about pupil age, and partly because in the early stages of the program several of the Kenya Ministry of Health public health nurses administered drugs to some older girls, judging the benefits to outweigh the risks. Treatment rates were considerably lower in 1999 than in 1998: among girls under thirteen years of age and all boys in treatment schools, approximately 57 percent received medical treatment at some point in 1999, while only 9 percent of the girls thirteen years of age and older received treatment. The drop in deworming treatment among girls younger than thirteen and boys appears to be due to two factors. First, a substantial subset of the initial sample had dropped out of school by 1999 and thus were unlikely to receive treatment, and second, the need to obtain signed parental consent in 1999 may have contributed to lower compliance rates.

Other sources of non-compliance with assigned treatment status were minor. The 1999 PSDP Pupil questionnaire surveyed pupils about their deworming treatment history and indicates that only five percent of comparison school pupils had ever received medical treatment for worms independently of the program. ${ }^{12}$ In an anthropological study examining worm treatment practices in a nearby region of

\footnotetext{
${ }^{12}$ A survey to assess the availability of deworming drugs in this area, conducted during May to July 1999, provides further evidence that few children in western Kenya receive medical treatment for helminth infections. All hospitals, health clinics, dispensaries, and pharmacies, as well as many local shops (dukas) in all towns and markets in the area were surveyed, for a total of 89 health facilities and shops. None of the 64 local shops surveyed had either the WHO-recommended broad-spectrum treatments for geohelminths (albendazole and mebendazole) or schistosomiasis (praziquantel) in stock on the day of the visit, though a minority of local shops carried cheaper but less effective deworming drugs (levamisole hydrochloride and piperazine). Although the survey results indicate that
} 
western Kenya (Geissler et al. 2000), in no case did a child or her parent ever obtain deworming drugs in a local store or clinic. ${ }^{13}$ Although pupils assigned to comparison schools could also potentially transfer to treatment schools to receive deworming medical treatment through the program, there is no evidence of large asymmetric flows of pupils into treatment schools. Table 5 indicates that the rate of transfers across schools was roughly symmetric across all three groups of schools in 1998 and 1999: among sample pupils, approximately two percent transferred into a different school in 1998, with nearly equal proportions transferring into Group 1, Group 2, and Group 3 schools. Approximately eight percent of pupils had transferred into a different school by the end of 1999, again with similar proportions transferring to all three groups. These relatively low and symmetric transfer rates are unlikely to have a substantial impact on the empirical results. As is standard in Intention-to-Treat (ITT) estimation, throughout the study pupils are assigned the treatment status of the school in which they were initially enrolled in early 1998, even if they later switched schools.

\section{Estimation Strategy}

The most important feature of the identification strategy is the project's randomized design. ${ }^{14}$ Since treatment status was randomly assigned across schools, program participation is not correlated in expectation with either observed or unobserved individual characteristics. This project design is likely to lead to smaller deworming treatment externalities for the comparison pupils than in the existing studies that randomize treatment within schools.

over eighty percent of clinics and pharmacies stocked albendazole, and that it can be obtained at a moderate price (approximately 100 shillings per dose), praziquantel is rarely found even in government clinics and pharmacies, and where praziquantel is stocked it is prohibitively expensive for most residents of the area, costing an average of nearly 900 Kenyan Shillings per dose (60 Kenyan Shillings equaled 1 U.S. dollar in 1999), several weeks of average wages per dose.

${ }^{13}$ Geissler et al. (2000) find that most schoolchildren self-treated helminth infections with local herbs. To the extent that children in Busia also use similar herbs and that these herbs have a positive effect on child health, the impact of the PSDP can be interpreted as the net benefit of deworming above and beyond the herbs, and as a lower bound on the effect of deworming in a setting in which children do not self-treat with such herbs.

${ }^{14}$ Recent econometric research emphasizes the value of experimental methods in identifying treatment effects (Heckman et al. 1998). Heckman and Smith (1995) discuss the potential limitations of social experiments. 
This section first presents how we estimate differences across treatment and comparison schools, and then discusses how we estimate cross-school externality effects. We employ both types of information to estimate overall treatment effects in sections 5, 6, and 7. Equation 1 illustrates how we estimate the difference in outcomes between treated and untreated schools using individual-level data.

$$
Y_{i j t}=a+\beta_{1} \cdot T_{1 i t}+\beta_{2} \cdot T_{2 i t}+X_{i j t}{ }^{\prime} \delta+u_{i}+e_{i j t}
$$

$Y_{i j t}$ is the individual educational outcome; $X_{i j t}$ are school and pupil characteristics; $T_{l i t}$ and $T_{2 i t}$ are indicator variables for school assignment to a first and second year of deworming treatment; and $e_{i j t}$ is the individual disturbance term, where $i$ refers to the school, $j$ to the student, and $t$ to the year of the program, $t \in\{1,2\}$. Disturbance terms are assumed to be independent across schools, but are clustered for observations within the same school, where the school effect is captured in the $u_{i}$ term. School and pupil controls include the average school result on the 1996 Kenya government District Mock exams for grades 5 to $8 ;^{15}$ the prevalence of moderate-to-heavy helminth infections in the pupil's grade and geographic zone (the pre-treatment average for 1998 and 1999); an indicator variable which equals one in both treatment and comparison schools for girls under thirteen years of age and all boys; indicators for school involvement in other ongoing non-governmental organization assistance projects; ${ }^{16}$ time controls (indicator variables for each six-month period capture the downward trend in school participation due to dropouts); and grade cohort indicator variables. These explanatory variables control for those pretreatment differences across schools that were present despite randomization, and they increase the precision of the coefficient estimates. Equation 2 is used to estimate the cross-school treatment externalities. We examine the impact of schools' geographic proximity to treatment schools using GPS school location data; children who live near treatment schools could have lower environmental exposure

\footnotetext{
${ }^{15}$ Average school scores from 1996 -- two years before the first year of the project -- were employed since the district mock exam was not offered in 1997 due to a national teacher strike. Average school exam scores are used because individual exam results are unavailable for 1996. However, the 1996 scores are corrected to be in units of individual-level standard deviations, and are thus comparable to the 1998 and 1999 test scores under the assumption that the decomposition of test score variance within and between schools was the same in 1996, 1998, and 1999.

${ }^{16}$ Twenty-seven of the sample schools were also receiving other assistance from ICS in 1998 and 1999. Since this assistance varied across years, school assistance indicators interacted with the year are also included as controls.
} 
to helminths, which would lead to less re-infection and lower worm burdens. The GPS data allow us to compute the total number of primary school pupils $\left(N_{d i t}\right)$ and the number of pupils in deworming treatment schools $\left(N_{d i t}^{T}\right)$ who attend other schools within a certain distance from school $i$ in year $t$ of the program. Given the total number of children attending primary school within a certain distance from the school, the number of treatment school pupils located nearby is exogenous and randomly assigned.

Equation 2 presents a linear regression specification for simplicity:

$$
\begin{aligned}
Y_{i j t}=a & +\beta_{1} \cdot T_{l i t}+\beta_{2} \cdot T_{2 i t}+X_{i j t}{ }^{\prime} \delta \\
& +\sum_{d}\left(\gamma_{d} \cdot N_{d i t}{ }^{T}\right)+\sum_{d}\left(\phi_{d} \cdot N_{d i t}\right)+u_{i}+e_{i j t}
\end{aligned}
$$

For example, in Sections 5 and 6, $d=03$ denotes schools that are located within three kilometers of school $i$, and $d=36$ denotes schools that are located between three and six kilometers away. ${ }^{17}$

Since treatment within schools was not randomized, we adopt a number of other approaches to assess within-school externalities, as discussed in Section 5.

\section{Deworming Treatment Effects on Health and Nutrition}

Children in deworming treatment schools experienced a range of health benefits, and there is evidence that these benefits spilled over to non-treated pupils. Subsection 5.1 first documents differences in health status between treatment and comparison schools, which we term the "naïve" treatment effect estimate; Subsection 5.2 provides evidence that health benefits spilled over both to untreated pupils in treatment schools and to neighboring comparison schools; and Subsection 5.3 combines information on differences in health between treatment and comparison schools with information on health externalities to construct estimates of (or at least bounds on) the effect of the program on the treated and on the population as a whole.

\footnotetext{
${ }^{17}$ We do not have data on the location of pupils' homes, and hence cannot examine if pupils living near Group 1 schools obtain greater externality benefits.
} 


\subsection{Differences Across Treatment and Comparison Schools}

Table 6 presents the prevalence of moderate-to-heavy helminth infections among Group 1 and Group 2 schools in early 1999, one year after the first round of medical treatment but before the second year of medical treatment. These data were collected during a Kenyan Ministry of Health parasitological survey of grade three to eight pupils in both Group 1 and Group 2 schools conducted in January and February 1999, when Group 2 schools had not yet been treated. The results indicate that the prevalence of moderate-to-heavy hookworm, roundworm, schistosomiasis, and whipworm infections was lower in Group 1 (1998 treatment) schools than in Group 2 (1998 comparison) schools: overall, 27 percent of pupils in Group 1 schools had a moderate-to-heavy helminth infection in early 1999 compared to 52 percent in Group 2 schools, and this difference is significantly different than zero at 99 percent confidence. The program was somewhat less effective against whipworm, perhaps as a result of the lower efficacy of single-dose albendazole treatments for whipworm infections, as discussed above. It is worth noting that the average difference in prevalence between treated and comparison schools is likely to have been even greater over the course of the year, since pupils whose infections were cleared may have been reinfected by the time of the January-February 1999 parasitological survey, nearly one year after the first round of medical treatment and three months since the second round of treatment. The rise in overall moderate-to-heavy helminth infections between 1998 and 1999 (refer to Table 3) is likely to be due to the extraordinary flooding in 1998 associated with the El Niño weather system. Flooding increased exposure to infected fresh water (note the especially large increases in moderate-to-heavy schistosomiasis infections), created moist conditions favorable for geohelminth larvae, and led to overflow of latrines and a major cholera outbreak.

Group 1 pupils also reported better health outcomes after the first year of deworming treatment: four percent fewer Group 1 pupils reported being sick in the past week, and three percent fewer pupils reported being sick often (these differences are significantly different than zero at 95 percent confidence). Group 1 pupils also had significantly better height-for-age - a measure of nutritional status - by early 1999, although their weight-for-age was no greater on average. 
Although Group 1 pupils had higher hemoglobin concentrations than Group 2 pupils in early 1999, the difference is not statistically different than zero. Anemia is the most frequently hypothesized link between worm infections and cognitive performance (Stoltzfus et al. 1997). Severe anemia is relatively rare in Busia: fewer then 4 percent of pupils in Group 2 schools (comparison schools in 1998) fell below the Kenya Ministry of Health anemia threshold of $100 \mathrm{~g} / \mathrm{L}$ in early 1999 before deworming treatment. This is low relative to many other areas in Africa, some of which have substantial helminth problems: a recent survey of studies of anemia among school children in less developed countries (Hall et al. 2000) indicates that there is considerably less anemia in Busia than in samples from Ghana, Malawi,

Mali, Mozambique, and Tanzania. Average hemoglobin levels among 12- to 14-year-old school children in these other African settings was $116.7 \mathrm{~g} / \mathrm{L}$, compared with $123.9 \mathrm{~g} / \mathrm{L}$ in Busia. ${ }^{18}$

Table 6 suggests that health education had a minimal impact on behavior, so that to the extent that the program improved health, it almost certainly did so through the effect of anthelmintics rather than through health education. As noted earlier, worm prevention education emphasized good hygiene, such as hand washing, in order to avoid ingesting roundworm and whipworm larvae; wearing shoes in order to avoid hookworm infection; and not swimming in infected fresh water, to avoid schistosomiasis.

However, there are no significant differences across treatment and comparison school pupils in early 1999 in terms of observed pupil cleanliness, the proportion of pupils wearing shoes, or self-reported exposure to fresh water.

\subsection{Health Externalities}

Deworming led to large positive health externalities both among untreated pupils in the treatment schools and among children in neighboring schools. Externality effects for the geohelminths tend to be

\footnotetext{
${ }^{18}$ One possible explanation for low levels of anemia in this area is geophagy (soil eating): Geissler et al. (1998) report that 73 percent of a random sample of children aged 10 to 18 years old in a neighboring region of Western Kenya reported eating soil daily. Given the average amount of soil children were observed eating daily, and the measured mean iron content of soil in this area, Geissler et al. conclude that soil provides an average of $4.7 \mathrm{mg}$ iron per day, over one-third of the recommended daily iron intake for children. Unfortunately, geophagy could also increase exposure to geohelminth larvae, promoting re-infection.
} 
localized, and are largest within treatment schools, while the externalities across schools are larger for schistosomiasis. The different results for geohelminths and schistosomiasis are consistent with their modes of transmission. Geohelminth eggs are deposited in the local environment when children defecate in the "bush" surrounding their home or school, rather than using a latrine or toilet. Schistosomiasis externalities are less likely to be tied to the immediate vicinity than geohelminths since the schistosomiasis parasite is spread through contact with infected fresh water. The water-borne schistosome may be carried considerable distances by stream and lake currents, and the snails that serve as its intermediate hosts are themselves mobile, both of which tend to extend the geographic reach of schistosomiasis externalities. Moreover, children are often infected with schistosomiasis by bathing or fishing in Lake Victoria, and children from different schools may fish or swim at the same points on the lake.

Table 7 provides evidence for externalities within treatment schools. In order to at least partially deal with potential biases due to selection into medical treatment, Group 1 pupils who did not receive treatment in 1998 are compared to Group 2 pupils who did not receive treatment in 1999, the year that Group 2 schools were incorporated into the treatment group. We compare the groups as of JanuaryFebruary 1999, when Group 1 schools had already been treated (in 1998) but Group 2 schools had not. If the process determining selection into treatment conditional on attending a treatment school is the same in 1998 and 1999, then equation 3 is an estimator of the within-school treatment externality, where $I(\text { treated })_{i j t}$ is an indicator variable that takes on a value of one if individual $i$ in school $j$ received treatment in year $t$ of the program: ${ }^{19}$

$$
\left.\left.E\left[Y_{i j t} \mid T_{1 i 1}=1, \text { I(treated }\right)_{i j 1}=0\right]-E\left[Y_{i j t} \mid T_{1 i 1}=0, T_{1 i 2}=1, \text { I(treated }\right)_{i j 2}=0\right]
$$

\footnotetext{
${ }^{19}$ Changes in the determinants of selection into medical treatment between 1998 and 1999 are likely to bias the coefficient estimates against finding an externality effect. Although sick people could theoretically be either more or less likely to obtain treatment, the results in Table 7 indicate that, both among Group 1 pupils in early 1998 and Group 2 pupils in early 1999, pupils who would remain untreated had somewhat higher initial rates of moderate-toheavy infection. Since a larger proportion of individuals remained untreated in 1999, the average initial health status of the 1999 untreated is likely to be somewhat better than that of the 1998 untreated.
} 
As shown in the bottom panel of Table 7, there are no significant differences in socioeconomic characteristics, weight-for-age, grade progression, or self-described health status between the untreated Group 1 pupils and Group 2 pupils who would later miss their opportunity for treatment, suggesting that the groups are essentially comparable aside from the effects of deworming treatment. Among girls under thirteen years of age and all boys - those children who were supposed to receive medical treatment through the project - rates of moderate-to-heavy infections were 21 percentage points lower among Group 1 pupils who did not receive medical treatment in 1998 (34 percent) than among Group 2 pupils who did not receive treatment in 1999 (55 percent), and this difference is significant at 95 percent confidence. These differences are negative and statistically significant for hookworm and roundworm, and negative but insignificant for schistosomiasis and whipworm; since the difference in whipworm infection between Group 1 and 2 schools was minimal and there is evidence that single-dose albendazole treatments are sometimes ineffective against whipworms, it is not surprising that evidence of withinschool externalities is weak for whipworm. ${ }^{20}$

Group 1 pupils who were treated in 1998 had a 24 percent chance of moderate-to-heavy infection in January to February 1999, while Group 2 pupils who would later obtain treatment in 1999 had a 51 percent chance of infection, for a difference of 27 percentage points. ${ }^{21}$ Thus the difference in the prevalence of moderate-to-heavy infections among the untreated was approximately three-quarters the difference in prevalence for the treated (21 percentage points versus 27 percentage points).

An additional source of evidence on local deworming externalities comes from a parasitological survey of children entering preschool who had not yet received medical treatment through the program. In 2001, before Group 3 schools had begun receiving deworming treatment, children entering preschool in Group 1 and 2 schools had 7.3 percentage points fewer moderate-to-heavy hookworm infections than

\footnotetext{
${ }^{20}$ Among girls older than twelve years of age in Group 1 schools, who under the medical protocol were not supposed to receive medical treatment through the program, rates of moderate-to-heavy helminth infections were thirteen percent lower than among similar girls in Group 2 schools, although this difference is not significantly different than zero (results not shown).
} 
those entering Group 3 schools (results not shown), and this effect is significantly different than zero at 90 percent confidence. Given that only 15.4 percent of the Group 3 preschool children suffered from moderate-to-heavy hookworm infections, this constituted a substantial reduction in the proportion of such infections, cutting rates by nearly half. Note that to the extent that children with moderate-to-heavy worm infections are less likely to attend preschool and thus to appear in our sample from the Group 3 schools, our estimates understate the true externality impact of deworming on the health of younger children.

There is also evidence for deworming health externalities across schools. Using GPS school location data, we examine rates of moderate-to-heavy helminth infections in both Group 1 and Group 2 schools in early 1999 as a function of their geographic proximity to other Group 1 schools; children who live near treatment schools should have lower environmental exposure to helminths, which would lead to less re-infection and lower worm burdens. ${ }^{22}$ As discussed above, the proportion of Group 1 schools located nearby is exogenous since schools' treatment status is randomly assigned.

Table 8 suggests that children who attend primary schools located near Group 1 schools had lower rates of moderate-to-heavy helminth infection: controlling for the total number of children attending any primary school within three kilometers, the presence of each additional thousand pupils attending Group 1 schools located within three kilometers of a school is associated with 12 percentage points fewer moderate-to-heavy infections, and this coefficient estimate is significantly different than zero at 95 percent confidence. Each additional thousand pupils attending a Group 1 school located between three to six kilometers away is associated with 8 percentage points fewer moderate-to-heavy infections, which is somewhat smaller than the effect of pupils within three kilometers, as expected, and is significantly different than zero at 90 percent confidence. Due to the relatively small size of the study area, we are unable to precisely estimate the impact of additional treatment school pupils farther than six kilometers away from a school, and thus we cannot rule out the possibility that there were also crossschool externalities at distances beyond six kilometers from each treatment school, and possibly for the

\footnotetext{
${ }^{21}$ Initial grade progression was actually lower among treated Group 1 pupils, suggesting that if anything, these pupils started off disadvantaged relative to their counterparts in Group 2 schools.
} 
study area as a whole, in which case the estimates presented in Table 8 (and discussed below) would be lower bounds on actual deworming externality benefits.

The cross-school externality effects are mainly driven by reductions in moderate-to-heavy schistosomiasis infections (Regression 2$) ;^{23}$ the effect on geohelminth infections is negative but insignificantly different than zero (Regression 5). Regression 3 indicates that schistosomiasis reductions in Group 2 schools - schools that were still untreated by early 1999 - account for most of these gains. In other words, schools that were treated themselves show little benefit from proximity to other treatment schools, but comparison schools are substantially better off if they are located near treatment schools. Schools near Lake Victoria, where schistosomiasis infections are concentrated, showed the largest externality gains: Regression 4 indicates that for schools located on Lake Victoria, the presence of an additional thousand pupils attending Group 1 schools located less than three kilometers away led to a 21 percentage point reduction in the prevalence of moderate-to-heavy schistosomiasis infections, while the presence of an additional thousand pupils attending Group 1 schools between three to six kilometers away led to a reduction of 27 percentage points.

A well-known epidemiological model of the transmission of helminth infections (Anderson and May 1991, p. 488) suggests that externalities of this magnitude are plausible. Using standard parameter values for schistosomiasis mansoni, ${ }^{24}$ the helminth that showed the largest externality effects in Table 8 , this model implies that in steady-state regular mass treatment against schistosomiasis in a random ten percent of the local population would lead to a 37 percent reduction in the total local worm burden, with over three quarters of this reduction due to the externality, while mass treating a random thirty percent of

\footnotetext{
${ }^{22}$ Measurement error in GPS locations - due to U.S. government downgrading of GPS accuracy until May 2000 leads to attenuation bias, making it more difficult to find treatment externalities.

${ }^{23}$ The schistosomiasis externality results are robust to including the proportion of Group 1 pupils in the surrounding area, rather than the total number of Group 1 pupils in the surrounding area, as an explanatory variable (results not shown).

${ }^{24}$ Using Anderson and May's terminology, these parameters values are: average lifespan $(A)=3$, basic reproductive rate $(R)=2$, aggregation parameter $(k)=0.5$, and efficacy of the drugs $(h)=0.8$. One third of local primary schools were treated in 1998, and school-aged children comprise approximately one third of the population of Kenya (World Bank 1999). However, given the high concentration of worm burden in children, and the fact that children are much less likely to use latrines than adults, and hence more likely to deposit larvae conditional on infection, we report estimates for both $\mathrm{g}=0.1$ and $\mathrm{g}=0.3$, where $\mathrm{g}$ is the proportion of the population treated.
} 
the local population against worms would lead to a reduction of 89 percent of the total local worm burden. The relatively short average lifespan of these helminths - approximately one to three years suggests that substantial externality benefits are likely to be apparent in the first year after treatment.

\section{Estimating Treatment Effects in the Presence of Externalities}

The estimation of treatment effects on the treated in this setting is complicated by the possibility of health externalities for untreated children in treatment schools. It is not valid to use assignment to a treatment school as an instrumental variable for actual medical treatment in the presence of such externalities (Angrist, Imbens and Rubin 1996) ${ }^{25}$ since the exclusion restriction fails to hold: assignment to a treatment school has a direct effect on pupil health outcomes due to the externality, rather than only affecting health through the likelihood of receiving medical treatment. Comparing prevalence before and after treatment is also unattractive, given that worms are affected by time-varying shocks, such as the flooding induced by El Niño.

We instead utilize information on cross-school health spillovers to construct estimates of the treatment effect on the treated. This calculation suggests that moderate-to-heavy helminth infections among children in this area were 11 percentage points lower on average in early 1999 as a result of health spillovers across schools - approximately one-quarter of overall moderate-to-heavy infection rates in Group 2 schools. To see this, note that the average spillover gain is the average number of Group 1 pupils located within $3 \mathrm{~km}$ divided by $1000\left(E\left[N_{03}^{T}\right]\right)$ times the average effect of an additional 1000 Group 1 pupils located within $3 \mathrm{~km}$ on infection rates $\left(\gamma_{03}\right)$, plus the analogous spillover effect due to schools located between three to six kilometers away from the school (refer to equation 2). Equation 4 presents this calculation, based on the externality estimates in Table 8:

Average cross-school externality reduction in moderate-to-heavy helminth infections

$$
\begin{aligned}
& =\gamma_{03} * E\left[N_{03,1}^{T}\right]+\gamma_{36} * E\left[N^{T}{ }_{36,1}\right] \\
& =[430 * 0.12+739 * 0.08] / 1000=0.11
\end{aligned}
$$


If there were spillovers beyond six kilometers, the average externality effect would be even larger.

The existence of substantial cross-school health externalities implies that the difference in average outcomes between treatment and comparison schools - the "naïve" treatment effect estimator understates the actual effects of mass deworming treatment on the treated. If externalities disappear completely after six kilometers, the true reduction in moderate-to-heavy infection rates among treated pupils in Group 1 schools would be the sum of the naïve treatment effect in early 1999 presented in Table 7 (27 percentage points) and the average cross-school externality gain (11 percentage points), which equals 38 percentage points. The treatment effect among untreated pupils in Group 1 schools would be the sum of the naïve treatment effect presented in Table 7 (21 percentage points) and the cross-school externality gain, or 32 percentage points. The magnitude of the cross-school externality is approximately thirty percent of the magnitude of the effect on the treated in Group 1 (11 divided by 38). However, to the extent that some deworming treatment gains spilled over beyond six kilometers, this estimate is still a lower bound on the actual effect of deworming. ${ }^{26}$ A lower bound on the total number of moderate-toheavy helminth infections eliminated through the program is thus:

Number of moderate-to-heavy helminth infections eliminated

$$
\begin{aligned}
& =(0.38) *(7,020 \text { Treated pupils in Group } 1 \text { schools }) \\
& +(0.32) *(2,797 \text { Untreated pupils in Group } 1 \text { schools }) \\
& +(0.11) *(19,493 \text { Pupils in Group } 2 \text { and } 3 \text { schools }) \\
& =5707 \text { infections }
\end{aligned}
$$

This is nearly one infection eliminated per treated child in Group 1 schools. Even this figure underestimates the actual total treatment effect of the program by excluding benefits for school-age children not enrolled in school, other community members not of school age - such as pre-primary children - and people who live in areas bordering Budalangi and Funyula divisions, whom we did not survey.

\footnotetext{
${ }^{26}$ Under spatial externality models in which a reduction in worm prevalence at one school affects neighboring schools - and this in turn affects their neighbors - some externalities would spill over beyond six kilometers. Although estimated externality effects beyond six kilometers are insignificant since standard errors are large, it is difficult to know whether externality effects do fade out after six kilometers.
} 


\section{Deworming Treatment Effects on School Participation}

This section argues that deworming increased school participation in treatment schools by at least seven percentage points, a one-quarter reduction in total school absenteeism. Deworming may improve school participation by allowing previously weak and listless children to attend school regularly or by improving children's ability to concentrate, which may make attending school increasingly worthwhile relative to other activities, such as agricultural labor, staying at home, or fishing in Lake Victoria. As with the direct health impact, deworming creates externalities in school participation both within and across schools; after accounting for those externalities we estimate that overall school participation in this area likely increased by at least 0.15 years per pupil treated. The response of school participation to deworming is larger than would be expected from retrospective estimates of the correlation between worm burden and school participation.

In analyzing school participation, our sample consists of all pupils enrolled in school or listed in the school register during the first term in $1998 .^{27}$ Since many pupils attend school erratically and the distinction between an absent pupil and a dropout is often not clearly made in school records, it is difficult to distinguish sharply between dropping out and long-term absenteeism; moreover, measuring pupil attendance conditional on not dropping out is unattractive since dropping out is endogenous. We therefore focus on a comprehensive measure of school participation: a pupil is considered a participant in school if he or she is present in school on a given day, and to be a non-participant if he or she is not in school on that day, regardless of the cause. Since school records are often badly kept, school participation

\footnotetext{
${ }^{27}$ Since many pupils who were recorded as dropouts in early 1998 re-enrolled in school at some point during the 1998 or 1999 school years, we include them in the sample. However, many initial dropouts were not assigned a grade by the NGO field staff, complicating the analysis of participation rates by grade. Such pupils are assigned their own grade indicator variable in Table 11. Some pupils have missing year of birth information due to absence from school on the days of questionnaire or exam administration, and certain assumptions need to be made regarding the treatment assignment status of girls with missing age information. Girls in treatment schools in preschool and grades 1, 2, and 3 are assumed to be eligible for treatment, and while those in grades 7 and 8 are assumed not to be, since all but a small fraction of girls in these grades meet the respective age eligibility criterion. Girls with missing ages in grades 4, 5, and 6 and those recorded as dropouts are assigned missing values, eliminating 99 girls from the sample of approximately 30,000 children, a small reduction in the sample. An additional 119 pupils are dropped from the sample due to both missing age and sex information.
} 
was measured during unannounced visits by NGO field workers to schools. Schools received an average of 3.8 school participation check visits per year in 1998 and 1999. Note that since the days of medical treatment were pre-announced, and the school participation figures do not include attendance on these days, effects on attendance are not due to children coming to school in the hope of receiving medicine.

\subsection{Differences across Treatment and Comparison Schools}

Table 9 presents differences in school participation across project groups and across time. Among girls younger than thirteen years old and all boys, the difference in school participation for the five posttreatment participation observations in the first year after medical treatment is 9.3 percentage points, and this is significantly different than zero at 99 percent confidence. The difference between Group 1 and Group 3 schools in 1998 is somewhat smaller, at 7.4 percentage points, but remains significantly different than zero at 95 percent confidence. The difference is larger among boys and young girls than among the older girls (5.7 percentage points), which is consistent with the fact that a smaller proportion of older girls received medical treatment (Table 4). The differences in 1999 school participation for boys and younger girls are also large and significantly different than zero at 90 or 95 percent confidence for both Group 1

(1998 and 1999 treatment schools) and Group 2 (1999 treatment schools), at 5.0 and 5.5 percentage points, respectively; these "naïve" treatment effect estimates are likely to represent lower bounds on the actual effect of deworming due to health spillovers across schools, as discussed below. The downward bias due to cross-school externalities is likely to be greater in 1999 , since more schools had been treated by that time.

School participation differences across treatment and comparison schools are particularly large among pupils in lower grades: in 1998 the average difference in school participation between treatment and comparison groups for preschool through grade 2 was 10.0 percentage points (significantly different than zero at 99 percent confidence), while for pupils in grades 6 to 8 it was 5.9 percentage points, and in 1999 the comparable gains for Group 2 pupils were 8.5 percentage points and 2.6 percentage points, respectively. The larger impact of treatment in lower grades may partially result from higher rates of 
moderate-to-heavy infection among younger pupils (Table 3). It is also possible that school participation is more elastic with respect to health for younger pupils: many Kenyan children drop out of school before reaching the upper primary grades, which implies that those older children who remain in school may be academically serious and thus determined to attend school despite illness.

The estimated difference in school participation between treatment and comparison schools in 1999 is somewhat smaller than that in 1998, although it is impossible to reject the hypothesis that the differences in 1998 and 1999 are the same. One possible explanation for the apparently smaller impact of the program in 1999 is the lower proportion of pupils taking deworming drugs compared to 1998 (Table

4). Deworming externalities for comparison schools are also likely to have been larger in 1999 than in 1998 since a larger proportion of local primary schools received medical treatment in 1999 (50 of 75 schools) than in 1998 ( 25 of 75 schools). Finally, the larger school participation differences between treated and comparison schools in 1998 may be due to the widespread El Niño flooding in this area in 1998, which substantially increased worm loads between early 1998 and early 1999 (compare Tables 3 and 6).

Figure 2 presents the time pattern of school participation rates from May 1998 to November 1999 for girls under thirteen and for all boys. Diamonds represent the differences in average school participation between Group 1 and Group 3 schools, and squares represent the difference between Group 2 and Group 3 schools. School participation rates for Group 1 schools are consistently higher than rates in Group 3 schools in both 1998 and 1999, and the gap stands at nearly ten percentage points by November 1999. Group 2 schools have lower school participation than Group 3 schools in 1998 - when both groups were comparison schools - but begin to show participation gains in early 1999. Participation gains in Group 2 schools increase gradually in the first half of 1999, possibly because the first round of 1999 treatment was not concluded until June.

Figure 3 presents histograms of average pupil school participation rates from May 1998 to November 1999 in Group 1 and Group 3 schools, and indicates that the school participation gains resulted 
primarily from improved attendance - a higher density in treatment schools at participation rates near one - although there were also noticeably fewer dropouts.

\subsection{School Participation Externalities}

The large participation gains among older girls - who were not supposed to be treated - in 1998 and 1999 provides the first hint that school participation externality benefits were substantial. Although the 1998 gains among older girls could have been driven in part by non-trivial rates of medical treatment, there were also large participation gains among older girls in Group 2 schools in 1999 despite the fact that only ten percent of them received medical treatment (Table 4). Table 10 presents evidence of externality school participation benefits among untreated pupils in Group 1 (1998 treatment) schools during the first year of the study. As in Table 7, Group 1 pupils who were untreated in 1998 are compared to Group 2 pupils who were later untreated during the two rounds of medical treatment in 1999, in order to address selection into treatment. Among girls under thirteen years old and all boys, the difference in May 1998 to March 1999 average school participation across these two groups of untreated pupils was 8.0 percentage points, which is significantly different than zero at 95 percent confidence, corresponding to one quarter of total pupil non-participation in this subsample. We also compare Group 1 pupils who were treated in 1998 to Group 2 pupils who were treated in 1999. The difference in their May 1998 to March 1999 school participation is 6.4 percentage points, amounting to one-third of overall non-participation in the comparison schools.

School participation externality estimates across schools using individual-level data are presented in Table 11. The dependent variable is average individual school participation in either the first year (May 1998 to March 1999) or the second year (April 1999 to November 1999) of the project. ICS school assistance controls, grade indicator variables, the school average exam score in 1996, the proportion of moderate-to-heavy infections in the pupil's standard and geographic zone, and time indicator variables for each six-month interval following the start of the project are included as explanatory variables in all 
specifications. Disturbance terms across observations in the same school are clustered, while errors across schools are assumed to be independent.

Regression 1 indicates that the average school participation gain for treatment schools relative to comparison schools across both years of the project is 5.6 percentage points, and this is significantly different than zero at 99 percent confidence. Regression 2 presents the "naïve" treatment effect estimate of six percentage points for the first year of treatment and four percentage points for the second year, with significance levels of 99 percent and 90 percent respectively. Confidence intervals are wide enough that we cannot reject the hypothesis that the effect is the same in both years. The coefficient estimates on other explanatory variables have the predicted signs: the school average exam score in 1996 is positively related to participation rates, and the proportion of moderate-to-heavy infections in the pupil's standard and geographic zone is negatively (though insignificantly) associated with participation (result not shown). The magnitude of the effects remains nearly unchanged when pupils initially recorded as dropouts in early 1998 are excluded from the sample (results not shown).

Regression 3 includes the numbers of treatment school pupils and total pupils attending primary school within three kilometers of the school as explanatory variables in order to explore the possibility of school participation externalities. The coefficient estimate on the number of local treatment pupils is positive and significantly different than zero at 90 percent confidence. The coefficient estimate implies that each additional one thousand pupils attending treatment schools within three kilometers leads to an increase of 3.4 percentage points in average school participation. Since there are 449 Group 1 pupils and 570 Group 2 pupils within three kilometers of the average primary school, this implies that school participation was approximately 1.5 percentage points higher on average throughout this area in 1998 due to deworming externalities, and 3.4 percentage points higher on average in 1999. Adding these figures to the "naïve" treatment effect estimates suggests that the effect of deworming on school participation in treatment schools was at least 7 percentage points in both 1998 and 1999, although even this is a lower bound, since it is possible that some benefits spilled over beyond three kilometers from treatment schools. 
The following calculation estimates the overall school participation gain due to the program. The program increased school participation in comparison schools by about 1.5 percentage points on average in 1998, when there were approximately three Group 2 and Group 3 pupils for every child treated in Group 1 schools. Children in treatment schools increased school participation by about 7 percentage points, and for every two treated children in a treatment school, there was approximately one untreated child. Hence treating one child led to an estimated lower bound increase in school participation of $(1 * 0.07)+(0.5 * 0.07)+(3 * 0.015)=.15$ school years.

We examined whether pupils in more heavily infected areas gain most from deworming treatment. However, the regressions indicate that average treatment gains are not significantly larger in areas with higher infection levels (results not shown). This may not be the case in a setting with more variation in local infection levels; the proportion of moderate-to-heavy infection is high across most of the Budalangi and Funyula divisions. The sample of pupils in the parasitological survey may also not be representative if sick children are less likely to attend school on the day of the survey, complicating interpretation of the coefficient estimates. ${ }^{28}$ The coefficient estimate on the interaction term between treatment and the local infection level is downward biased to the extent that cross-school deworming externality benefits are greatest in areas with the highest infection rates. As discussed further below, attenuation bias due to measurement error in the parasitological data is also a concern in this setting and would mean that coefficient estimates are further biased towards zero.

The coefficient estimates on interactions between pupil characteristics - including latrine ownership at home, livestock ownership, initial weight-for-age and height-for-age, and gender - with treatment assignment indicators are all insignificantly different than zero (results not shown).

The coefficient estimates on the interactions between treatment indicators and distance to lake Victoria - which is highly correlated with the prevalence of schistosomiasis in this area (refer to Table 3

\footnotetext{
${ }^{28}$ The deworming treatment effect may also be non-monotonic with respect to local infection intensity if areas with many serious infections also suffer disproportionately from other health problems that lead to persistently low school attendance. Local rates of moderate-to-heavy helminth infections are in fact positively correlated with selfreported malaria across geographic zones in this area (results not shown).
} 
and to Brooker et al. 2001) - are not significantly different than zero, indicating that school participation treatment effects among those infected with both schistosomiasis and geohelminths are not considerably larger than the effects for children with geohelminth infections alone.

\subsection{Comparing Retrospective and Experimental Estimates}

Retrospective estimates of the impact of worms on school participation are considerably smaller than would be suggested by the experimental estimates. This may be explained by attenuation bias in the retrospective estimates, a form of selection bias, and complementarity across students in school participation.

Regression 4 in Table 11 retrospectively examines the association between moderate-to-heavy worm infection and school participation in the first year after the start of medical treatment (May 1998 to March 1999). It is restricted to the sub-sample of pupils in grades three to eight for whom there is 1999 parasitological data. We thus lack information on the preschool, grade 1, and grade 2 pupils that exhibit the largest experimental treatment effect estimates. Regression 4 indicates that pupils who were moderately or heavily infected in early 1999 had significantly lower participation rates (2.8 percentage points lower). However, the retrospective estimate of 2.8 percentage points is smaller than might be anticipated given the 2 to 7 percent difference in school participation rates between treatment and comparison schools for this older age group (Table 9). Given that moderate-to-heavy infections in early 1999 were 25 percentage points lower in treatment schools, if only pupils with moderate-to-heavy infections increased their school participation, the experimental estimates would imply that on average each of these pupils increased school participation by 8 to 28 percentage points, rather than the 2.8 percentage point retrospective estimate. Of course, the average difference over the year in infection rates between treatment and comparison schools may have been larger than 25 percentage points, since many treated children may have had moderate-to-heavy infections cleared or reduced to lower levels as a result of treatment, only to re-acquire moderate-to-heavy infections by the time of the next parasitological 
survey. If more pupils actually benefited from medical treatment, the implied school participation improvement among the moderately to heavily infected would be smaller.

Nonetheless, the retrospective estimate may initially seem surprisingly small given the possibility of negative omitted variable bias. For example, if children with lower socioeconomic status - which is imperfectly observed - are both more likely to drop out of school and are more likely to have serious worm infections, the retrospective estimate would be more negative than the experimental estimate. (It is worth noting that omitted variable bias could also go the other way; for example, dynamic and energetic children may both play more in Lake Victoria - putting them at risk of schistosomiasis - and be more successful students.)

One potential explanation for why experimental estimates of the deworming effect are larger than suggested by retrospective estimates is error in measuring the severity of disease, leading to attenuation bias. Measurement error is likely to be substantial and could take several forms: pure measurement error performing egg counts (from stool samples) in the lab; time variation in worm burden, so that those individuals who were moderately to heavily infected in early 1999 were not necessarily the same ones who were most heavily infected over the course of the school year; coarseness in our binary measure of worm burden; heterogeneity in the impact of different worm species on school participation; and interactions among worms that are not captured by our binary measure, so that some individuals who are classified as having multiple light worm infections in fact suffer from substantial morbidity. Moreover, epidemiologists have argued that there is a noisy relationship between worm egg counts - the basic measure of infection intensity in this and many other studies - and actual worm infection burden (Medley and Anderson 1985), further exacerbating measurement error.

Under certain assumptions, heterogeneous treatment effects may interact with sample attrition to further exacerbate estimation biases. This is because those pupils for whom high measured worm burdens 
are not associated with absenteeism are more likely to be in school on the day of the parasitological exam and hence to make it into our sample. ${ }^{29}$

The difference between retrospective and experimental estimates of the impact of worms could also be due in part to complementarities among pupils in school participation. For example, if the preschoolers, first-graders, and second-graders for whom we estimate the largest school participation effects stay home sick with worms in the comparison schools, their older sisters may have to stay home to take care of them. This may partially explain the relatively large treatment effects we find for older girls. ${ }^{30}$ To take another example, children may be more inclined to go to school if their friends are also in school, so school participation gains in treatment schools may partially reflect increased school participation among children who were not infected. None of these effects would be picked up in a regression of school participation on worm level, or even in a prospective study in which treatment is randomized at the individual level, but they are captured in a prospective evaluation in which treatment is randomized at the school level.

\section{Test Scores and Promotion Rates}

Deworming could potentially improve test scores both by increasing time spent in school and by improving learning while pupils are in school. Deworming could also potentially reduce test scores through congestion or negative peer effects.

The first positive channel, increasing the total amount of time spent in school, is likely to be weak given the observed cross-sectional relationship between school participation and test performance. The ICS exams in English, Mathematics, and Science-Agriculture - which are modelled on Kenyan Ministry

\footnotetext{
${ }^{29}$ For example, suppose that half those for whom egg counts would suggest high worm burdens actually have normal school participation, while the other half of children with high measured worm burdens have dropped out or attend rarely, and have 1/3 normal school participation. On average, then, those with high recorded egg counts have 2/3 normal school participation. However, since those children with high measured worm burden whose attendance is unaffected are sampled for the parasitological survey three times as often as those with $1 / 3$ normal participation, the group of moderately -to heavily infected children will appear to have a school participation rate $3 / 4 * 1+1 / 4 * 1 / 3$ $=5 / 6$ the normal level, so the estimated effect of moderate-to-heavy helminth infections on school participation will be $-1 / 6$, one-half the true value of $-1 / 3$.

${ }^{30}$ Since we do not have data on family relationships among pupils, we cannot directly test this hypothesis.
} 
of Education exams - were administered in 1998 and 1999. The average score across all subjects is employed as the principal test score outcome measure for each set of tests, although the basic results are unchanged if subjects are examined separately (regressions not shown). ${ }^{31}$ For both 1998 and 1999, test scores were normalized to be mean zero and standard deviation one among comparison pupils initially enrolled in the same grade in early 1998.

Regression 1 of Table 12 shows the cross-sectional relationship between individual school participation and individual test score performance: the coefficient estimate on average individual school participation is approximately 0.6 . The coefficient estimate suffers from attenuation bias due to measurement error, since the school participation measure for each individual is the average of only 3.8 participation observations per year. It is straightforward to correct this coefficient estimate for attenuation bias since the average participation rate and the number of participation observations are known. ${ }^{32}$ The corrected coefficient estimate is approximately 1.8. This implies that a year of absence is associated with a 1.8 standard deviation fall in test scores, while a ten percentage point gain in attendance is associated with a 0.18 standard deviations higher score on the ICS exam. If deworming leads to test score gains solely through improvements in attendance, and average school participation in treatment schools exceeds that in comparison schools by approximately 5.6 percentage points as a result of deworming (Table 11),

\footnotetext{
${ }^{31}$ Although the ICS tests for 1998 and 1999 are similar in content, they differ in two important respects. The 1998 exam features multiple-choice questions while the 1999 test featured short answers. Second, while each grade in 1998 was administered a different exam, in 1999 the same exam - featuring questions across a range of difficulty levels - was administered to all pupils in grades 3 to 8 . Administering a single exam to all pupils is particularly useful if grade promotion rates differ across treatment and comparison schools. Government District Mock exams in English, Maths, Science-Agriculture, Kiswahili, Geography-History, Home Science, and Arts-Crafts were also administered in both years. Treatment effect estimates are similar for both sets of exams (results not shown). There are several reasons to focus on the ICS exams. Exam participation was higher on the ICS exam than on the District Mocks - for example, 84 percent of enrolled pupils took the ICS exam in 1998 while the corresponding rate for the Mocks was 66 percent - presumably since pupils must pay an exam fee to sit for the Mocks, while taking the ICS exam was free. The ICS exam estimates thus contain average treatment effect information for a larger proportion of pupils. Moreover, treatment schools showed far higher participation than comparison schools on the Mocks, potentially exacerbating selection biases.

32 The following calculation is not exactly correct, since the number of participation observations differs across individuals, but it serves as a useful approximation. The average participation rate among this subsample of pupils is 0.886 , which implies that the variance of a single participation observation is $(0.886)(1-0.886)=0.101$. Pupils are observed 3.8 times per year on average, which implies that the sampling variance of average annual participation $\left(\sigma_{S}^{2}\right)$ is approximately 0.026 ; the total variance in average annual school participation $\left(\sigma_{T}^{2}\right)$ is 0.039 . The true coefficient estimate on average annual attendance $\beta$ is related to the coefficient estimate $b$ by the standard attenuation bias formula: $\beta=b\left(\sigma_{T}^{2} / \sigma_{T}^{2}-\sigma_{S}^{2}\right)$.
} 
the estimated "effect" of deworming on test scores in the absence of omitted variable bias would be $(0.056)^{*}(1.8)$, or approximately 0.1 standard deviations.

However, the coefficient estimate on average school participation in this regression is likely to overstate the true impact of increased participation on test scores for two reasons. First, it reflects not only the causal impact of higher participation on test scores, but also unobserved omitted pupil characteristics correlated with both test scores and school participation. Second, the coefficient estimate on school participation is likely to reflect the impact of better attendance over the course of a child's entire school career, whereas this study only examines attendance gains over one or two years; 5.6 percentage points higher school participation for two years translates into fewer than twenty additional days of schooling, and might plausibly have only a limited effect on academic performance. For example, if omitted variable bias accounted for half of the observed correlation between test scores and school attendance, and if the remainder of the correlation reflects the effects of the past five years of schooling on academic performance, then one would expect that increasing attendance by 5.6 percentage points for two years would increase test scores by less than 0.02 standard deviations.

The second channel through which deworming could increase scores is by improving the efficiency of learning per unit of time spent in school. However, since severe anemia is rare in this area (Table 6) and there were only small differences in anemia between treatment and comparison schools, the most frequently hypothesized link between worm infections and cognitive performance (Stolzfus et al. 1997) may not have been operative during the study.

On the other hand, deworming could potentially have reduced test scores in treatment schools through congestion and peer effects. Classrooms were more crowded in treatment schools as previously ill children attended school more regularly, and the presence of these additional pupils in the classroom may have imposed negative learning externalities on other pupils. For example, it may be more difficult to maintain classroom discipline in larger classes, and teachers may need to repeat concepts extra times for low-achieving students, who would have dropped out in the absence of the deworming program. Assuming that the class size effect in Angrist and Lavy (1999) is linear, and that the Israeli relationship 
between class size and academic outcomes also applies in Kenyan primary schools, deworming participation gains of the magnitude we find would lead to a drop of between 0.02 to 0.05 standard deviations in average exam scores. ${ }^{33}$

The estimated differences in test scores between pupils in treatment and comparison schools in regression 2 are -0.041 standard deviations for the first year post-treatment and -0.045 standard deviations for the second year, neither of which is significantly different than zero (Regression 2, Table 12). The 1996 average school scores on District Mock exams are included in all regressions as a control for pretreatment school quality. The coefficient estimate on the number of treatment pupils attending primary schools within three kilometers is insignificantly different than zero (results not shown).

The results could potentially have been affected by differential attrition across treatment and comparison schools, if the additional treatment school pupils who participated in the exam after deworming were below-average performers. In the 1998 ICS exams, 85 percent of Group 1 pupils sat, compared to 83 percent in the comparison Group 2 and Group 3 schools. To address this issue, regression 3 restricts the sample to pupils who were administered the 1998 pupil questionnaire, eliminating over twenty percent of the sample and much of the potential exam participation bias since nearly identical proportions of these pupils took the ICS exam in treatment and comparison schools. Estimates using this restricted sample are similar to those using the complete sample and remain insignificantly different than zero at traditional confidence levels, suggesting that at least among this subsample, deworming did not substantially raise test scores.

We can only measure the impact of the program on test scores among the roughly 85 percent of pupils who took the exam, so it remains possible that benefits may have accrued disproportionately among the 15 percent of pupils who missed the exam, especially if they suffered from the most intense helminth infections. However, we do not find a strong association between worm burden and the

\footnotetext{
${ }^{33}$ The increase from thirty to forty pupils in Israeli grade four and five classes is associated with a drop of approximately 0.13-0.29 standard deviations in academic achievement test scores. The average class size in Kenyan primary schools, between grades 3 to 8 , is approximately 30 pupils, and the average increase in school participation as a result of the deworming program was approximately 5.6 percent, which increases average class size to 31.7 pupils.
} 
likelihood of missing the exam within the sample of students in the parasitological sample. ${ }^{34}$ A higher promotion rate could result if deworming increased learning among weak students who did not take ICS exams. Promotion rates in treatment schools between 1998 and 1999 are in fact two percentage points higher than in comparison schools, although this difference is not significantly different than zero (results not shown).

Given the observed cross-sectional relationship between participation and test scores, the absence of a strong time-in-school effect on test scores is not surprising. However, the data are not consistent with the hypothesis of a strong effect on the efficiency of learning per unit of time in school for the subsample who took the test. It is worth noting that several other primary school interventions in this region of Kenya - including textbook provision (Glewwe, Moulin, and Kremer 1999), school grant provision, and an incentive scheme to promote teacher attendance - have also had limited success in improving academic test scores.

\section{Cost Effectiveness and Welfare Analysis}

The controversy over whether mass school-based deworming treatment should be a public policy priority for the poorest countries can be approached in several ways. Under the "health cost effectiveness approach," health projects are considered cost-effective up to some threshold cost per Disability-Adjusted Life Year (DALY) saved, perhaps $\$ 25$ to $\$ 100$ per DALY in the poorest countries. We also consider the “educational cost effectiveness" of promoting school participation through deworming rather than through alternative educational interventions. The "human capital investment approach" estimates the

\footnotetext{
${ }^{34}$ A subset of pupils who did not take the 1998 ICS exam (including dropouts) were followed up in twenty of the seventy-five deworming schools and encouraged to sit for the exam shortly after the ICS exam was administered in school, allowing us to impute test scores for dropouts. In total, 214 pupils were administered the follow-up exam in these schools. Among grade 3-8 pupils with missing ICS exams, similar proportions were administered the followup exam in Group 1 (treatment) schools - 34 percent - and Group 2 and Group 3 (comparison) schools - 32 percent - suggesting that selection bias is unlikely to be large (although it remains possible). Missing 1998 ICS test score data was imputed in two steps. First, the normalized test scores of the follow-up pupils were regressed on a set of indicator variables for their grade, geographic zone, and school assistance group (assistance from other NGO projects) separately for Group 1, Group 2, and Group 3 schools. It was impossible to condition on a broader set of covariates since many of the pupils with missing exam data are also missing pupil questionnaire data. Second, missing test score values for other pupils with missing tests are imputed as predicted values of this regression, again
} 
rate of return to deworming in future earnings. The "externality approach" attempts to identify the subsidy which would lead individuals to fully internalize treatment externalities. ${ }^{35}$

The externality and school participation effects examined in this paper turn out to play an important role under a variety of approaches. For example, as discussed below, we find that under the health cost effectiveness approach, treatment of schistosomiasis is extremely cost effective, but that a naïve estimate ignoring externalities would severely underestimate its cost effectiveness. Treatment of geohelminths would not meet standard cost-effectiveness criteria in the poorest countries based on its health impact alone, but is extremely cost effective relative to other ways of increasing school participation in the area that have been examined using prospective evaluations. While estimates of the long-run labor market impact of deworming are speculative, our best estimate is that deworming is an excellent human capital investment given its impact on school participation, and that the externalities from deworming justify fully subsidizing treatment.

\subsection{Health Cost Effectiveness}

Annual government expenditure on health in Kenya was approximately five U.S. dollars per capita from 1990 to 1997 (World Bank 1999), so mass deworming is clearly only one of many health interventions competing for scarce resources. For example, the vaccination rate against measles and DPT (diptheria, pertussis, and tetanus) among Kenyan infants of less than one year of age was just 32 percent in 1997 (World Bank 1999), and these vaccinations are thought to be highly cost effective, at only 12 to 17 U.S. dollars per disability-adjusted life year (DALY)saved.

We use deworming program cost estimates from the Partnership for Child Development (PCD), which reports costs of 0.49 US dollars per pupil per year in a large-scale government intervention in Tanzania. These costs are probably more relevant for potential large scale programs than the PSDP costs,

separately for Group 1, Group 2, and Group 3 schools. Treatment effect estimates remain negative and insignificantly different than zero using this augmented sample (results not shown).

${ }^{35}$ We consider various approaches since restricting public health subsidies to the goal of addressing treatment externalities may not be appropriate in the presence of credit market imperfections, behavioral and information problems, or imperfect within-household altruism, all of which are concerns in this setting. 
since the PSDP was not able to fully realize economies of scale in drug purchase and delivery, and since it is difficult to disentangle evaluation and delivery costs in the PSDP. ${ }^{36}$

According to the World Health Organization, schistosomiasis infections are associated with much greater disease burden per infected individual than geohelminths, on average. Given data on the burden of disease in WHO (2000), and the number of people infected worldwide, the implied average DALY burden per person infected is 0.0013 for hookworm; 0.0004 for roundworm; 0.0005 for whipworm; and 0.0097 for schistosomiasis. Approximately 18 percent of those infected with helminths globally are thought to suffer morbidity as a result of their infection, and in our cost-effectiveness calculations we assume that the entire disease burden is concentrated among individuals with moderate-to-heavy infections (Bundy et al. 2001). ${ }^{37}$

In calculating the overall reduction in disease burden due to the program, we consider direct treatment effects (corrected for cross-school externalities) on the treated in treatment schools from Table 7; externality effects (corrected for cross-school externalities) on the untreated in treatment schools from Table 7; and externalities for untreated pupils in comparison schools, from Table 8. We only consider cross-school externalities for schistosomiasis, since only these were significantly different than zero in Table 8. Given the project's randomized design, we assume that Group 3 schools (which are lacking 1999 parasitological data) experienced the same externality benefits as Group 2 schools through early 1999 when neither group had yet received treatment.

Summing these three components of the treatment effect, the total number of DALY's averted as a result of the program is 256 , which translates into a cost of approximately $\$ 12$ per DALY averted, using the costs of the PCD program in Tanzania. This estimate still ignores the health spillover benefits for other untreated children and adults in the treatment area. Even if the PCD costs were underestimated by a

\footnotetext{
${ }^{36}$ For example, the PSDP used trained nurses, held meetings to explain consent procedures, individually recorded the names of all pupils taking medicine, and was headquartered in Busia town, several hours drive away from many of the project schools. All of these costs might have been unnecessary in a full-scale program that did not include an evaluation component. Overall, excluding the costs most clearly linked to the evaluation yields a cost per pupil treated through the PSDP in 1999 of 1.46 US dollars, with nearly half of this cost in drug purchases.

${ }^{37}$ Note that this implies that the burden of disease per infected individual in our sample is greater than the world average; this is appropriate, since levels of moderate-heavy infection are relatively high in this setting.
} 
factor of two, deworming would still be among the most cost-effective health interventions for less developed countries.

The externality benefits of treatment (both within and across schools) account for 61.1 percent of the DALY reduction. A naïve treatment effect estimate that failed to take externalities into account would underestimate program treatment effects, not only because externalities would be missed, but also because gains among the treatment group would be underestimated. Consequently, the naïve estimate would overestimate the cost per DALY averted by almost a factor of five, leading one to mistakenly conclude that deworming does not meet the strictest cost-effectiveness standards.

The health gains are overwhelmingly attributable to reductions in the prevalence of moderate-toheavy schistosomiasis: 94 percent of the total DALY reduction is due to averted schistosomiasis. We can separately calculate the cost per DALY averted for the geohelminths; geohelminth infections lead to less morbidity according to the $\mathrm{WHO}$, but are also much cheaper to treat than schistosomiasis. Assuming that all drug delivery costs remain the same, but considering only albendazole drug costs in this exercise, the cost per geohelminth DALY averted would be $\$ 155$, which implies that mass geohelminth treatment in areas without schistosomiasis would not meet strict cost effectiveness criteria in the poorest countries based purely on its health impact. ${ }^{38}$ As discussed below, however, it is likely to be justified on other grounds.

\subsection{Educational Cost Effectiveness}

Deworming was by far the most cost-effective method of improving school participation among a series of educational interventions implemented by ICS in this region of Kenya that were subject to randomized evaluations. ICS has implemented and evaluated textbook provision, grants to school committees, training for teachers, and incentives for teachers based on student test scores and dropout rates. Given that the deworming program increased school participation by approximately 0.15 years per

\footnotetext{
${ }^{38}$ The cost per DALY for geohelmnith treatment would be lower if albendazole were delivered as part of an ongoing school-based project in areas where schistosomiasis is being treated, although schools would still have to be visited at least once more per year for an additional round of for treatment with albendazole.
} 
treated child (see Section 6), a large scale program with the Tanzania PCD cost of 0.49 US dollars per child would cost approximately $\$ 0.49$ / 0.155 , or $\$ 3.27$ US dollars per additional year of school participation, including both effects on the treated and externality benefits.

Aside from deworming, the program which was most successful in increasing school participation was the ICS Child Sponsorship Program (CSP). This program had a number of components, but the key component was substantially reducing the cost of school attendance by paying for the uniforms that Kenyan children are required to wear to school. Even under optimistic assumptions, reducing the cost of schooling in this way costs approximately $\$ 99$ per additional year of participation induced. ${ }^{39,40}$

\subsection{Deworming as Human Capital Investment}

Given that the PSDP increased school participation but not test scores, any calculation about its effects on human capital accumulation must necessarily be speculative. Nonetheless, a rough calculation suggests that the labor market benefits of deworming may far outweigh its costs. Knight and Sabot (1990) estimate returns to education in Kenya controlling for a wide range of variables including cognitive tests. They decompose the returns to education into a return to cognitive performance (on tests of literacy, numeracy, and reasoning) and a direct return to years of schooling and find that years of schooling alone account for approximately 40 percent of the 17 percent rate of return to education. ${ }^{41}$ If one interprets this as a human capital effect rather than a signalling effect, the return to an additional year of primary school would be approximately 7 percent.

\footnotetext{
${ }^{39}$ Our assumptions about the cost of attracting children to school by reducing the cost of school are optimistic because we assume that CSP's impact on school participation was due entirely to reducing the cost of school. The program also provided textbooks and new classrooms; another evaluation in the same area found that provision of textbooks did not affect school participation. School participation improved immediately through CSP, while classrooms were only provided several years into the CSP program. In any case, if textbook or classroom costs are included, deworming appears even more cost effective.

${ }^{40}$ Even under the extreme assumptions that uniforms are a pure transfer to parents so the social cost of the CSP is simply the deadweight loss associated with raising tax revenue, and that households obtained no consumption benefits from the deworming program, the social cost of deworming per year of extra school participation is likely to be far lower than that of purchasing school uniforms.
} 
After correcting for the fact that comparison schools were also affected, the program increased school participation by 0.15 years per pupil treated, as discussed in Section 6. Output per worker in Kenya is 570 U.S. dollars (World Bank 1999). To calculate the effect on the net present value of discounted wages, we assume that sixty percent of output per worker in Kenya is wages and that wage gains from higher school participation are earned over forty years in the workforce and discounted at ten percent per year. Against this long-run wage increase, we set the opportunity cost of schooling, as children may work rather than attend school. However, children who are heavily infected with worms are unlikely to be particularly productive as workers and may not work at all. We assume that the average primary school child who misses school due to worms is half as productive as the average adult; this is likely to represent an upper bound on productivity of children in general, let alone sick children. ${ }^{42}$ Under these assumptions, deworming increases the net present value of wages by more than $\$ 20$ per treated child at a cost of only $\$ 0.49$. If one assumes that the children who missed school as a result of worms were only 20 percent as productive as adults, then the benefit-cost ratio for the program still exceeds ten even if the rate of return to an additional year of schooling is only 1.5 percent (calculations not shown).

\subsection{Externalities and Optimal Deworming Subsidies}

The externality benefits of deworming in terms of future wages (as calculated in Section 8.3) alone appear to be far larger than the costs of deworming, suggesting a rationale for subsidies even under an orthodox externalities analysis. The total net externality gain (within and across schools) per child treated is then $\$ 11.70$ per child treated, over twenty times as large as the $\$ 0.49$ cost of deworming, suggesting that a large government deworming subsidy is optimal. This figure excludes the potentially

\footnotetext{
${ }^{41}$ Knight and Sabot (1990) performed this decomposition for returns to secondary education, but it serves as a useful approximation in the absence of a similar decomposition for primary education.

${ }^{42}$ Udry (1996) finds that children's agricultural labor productivity is much less than one-half that of adult agricultural labor productivity in another rural African setting (Burkina Faso).
} 
substantial benefits experienced by school-age and younger children not enrolled in school, by adults in these communities, and individuals in areas bordering the study area. ${ }^{43}$

To summarize, treatment of schistosomiasis appears to be an extremely cost-effective health intervention under standard health cost effectiveness criteria for less developed countries, although this is less true for the treatment of geohelminths. Even in areas with geohelminths but little schistosomiasis, deworming is a cost-effective way to boost school participation relative to other educational interventions evaluated in the same area, such as directly reducing the cost of school through the provision of school uniforms. It also appears likely that deworming can be justified as a human capital investment. Finally, the externality benefits from deworming are sufficient to justify fully subsidizing treatment in the program we examine. Since helminth transmission does not respect local primary school boundaries, and externalities across schools are substantial (Tables 8 and 11), subsidies may be warranted at levels higher than local school committees, such as the district or provincial government level.

Note that while we can conclude that there were substantial externalities from the deworming treatment provided from the PSDP, it is difficult to draw conclusions about the optimal deworming subsidies in the absence of a fully-fledged behavioral and epidemiological model. This is because the marginal positive externalities from treatment depend on how many others are also being treated. While positive externalities from PSDP were large on average, it is difficult to identify marginal positive externalities, and even harder to gauge how large treatment externalities would be at alternative coverage levels. We also do not know how coverage is likely to vary with subsidies, although we hope to collect such information in the future. Depending on epidemiological parameters, some incomplete level of coverage could potentially be sufficient to eliminate the disease from the population, and in this case there would be no purpose in raising subsidies above the amount that would generate this level of coverage.

\footnotetext{
${ }^{43}$ Even if one believes that the increased school participation led to negative congestion externalities by increasing class size, the positive externalities are easily large enough to pay for the additional teachers needed to offset any increase in class size. To see this, note that deworming increased school participation by 0.15 years per pupil treated, and that with one teacher per thirty pupils, this would require an additional 0.005 teachers. If teachers cost $\$ 2000$ per year, this amounts to $\$ 1$ per treated pupil. So a program that provided deworming and additional teachers would generate $\$ 11.70$ in positive externalities at a cost of $\$ 1.49$ per pupil.
} 
Caution is similarly needed in extrapolating these results to areas with different worm prevalence. While the direct benefits of deworming may be proportional to worm burden, the externality benefits are likely to vary non-linearly with worm burden. Additional research is needed to determine optimal deworming subsidies in this and other settings.

\section{Conclusion}

To summarize the results of the current study, a school-based deworming program in Kenya led to at least a seven percentage point average gain in primary school participation in treatment schools, reducing overall school absenteeism by one quarter. Treatment created positive health and school participation externalities for untreated students in the treatment schools and for pupils in neighboring schools. A rough calculation suggests that these spillovers alone are sufficient to justify not only fully subsidizing deworming treatment, but even paying people to receive treatment.

Our results have methodological implications for the literature on the educational effects of deworming. The existing literature primarily focuses on test scores, but our results suggest that researchers should also examine the effects on school participation, where we find large impacts. Given our findings of an impact on school participation, earlier studies examining test scores may be subject to attrition bias. Most important, our results also suggest that existing estimates of the effect of deworming, based on studies that randomize treatment within a school, doubly underestimate the effects of deworming programs. First, they entirely miss the external effects of deworming, and second, they underestimate the direct effects to the extent that control group pupils benefiting from deworming externalities bias existing treatment effect estimates toward zero. This problem can be addressed by randomizing at the level of larger units such as schools, rather than at the individual level, although our finding of substantial treatment spillovers across schools suggests that units even larger than the school would be ideal.

The large improvement in school participation following deworming found in this study points to the role that tropical diseases such as intestinal worms may play in reducing educational attainment in 
sub-Saharan Africa, the region with the highest prevalence of helminths and other tropical diseases

(World Bank 1993). This provides microeconomic support for claims that Africa's high tropical disease

burden is a causal factor contributing to its low income. ${ }^{44}$ To the extent that the treatment of other

tropical infectious diseases also generates spillovers benefits similar to deworming, the externality

findings of the current study may also provide an additional rationale for a substantial public role in

subsidizing medical treatment for infectious diseases in less developed countries. ${ }^{45}$

\footnotetext{
${ }^{44}$ However, even under optimistic assumptions, the impact of deworming on wages probably cannot explain more than a small fraction of the enormous income gap between African and industrialized countries. If school-based deworming were equally as effective through Kenya as in Busia (which is unlikely, since the study area was selected precisely because of its high helminth infection prevalence), educational attainment would be seven percent higher in the country as a whole, or approximately $(0.07)^{*}(6$ years $)=0.42$ years. If an additional year of primary schooling has a seven percent return, this gain in educational attainment translates into approximately three percent higher average wages. However, according to World Bank figures, U.S. GDP per capita is over eighty times are large as Kenyan per capita income.

${ }^{45} \mathrm{An}$ important issue for future research is why parents are not currently purchasing deworming drugs for their children, given the moderate costs of the drugs and their potentially important health, educational, and labor market benefits, and why a large minority of children did not receive deworming drugs through the program. We are currently investigating the role that rural social networks play in the transmission of knowledge about health, and about worms in particular; the randomized provision of the deworming treatment intervention through the project allows an examination of information diffusion, peer effects, and social learning (Miguel and Kremer 2001). In 2001, the NGO introduced a parent user fee for participation in the deworming project, and we will explore which parents participate in cost-sharing and their reasons for participating.
} 


\section{References}

Adams, E.J., Stephenson, L.S., Latham, M.C., and Kinoti, S.N. (1994). "Physical Activity and Growth of Kenyan School Children with Hookworm, Trichuris trichiura and Ascaris lumbricoides Infections Are Improved after Treatment with Albendazole.” The Journal of Nutrition, 124 (8), 1199-1206.

Anderson, R.M., and R.M. May. (1991). Infectious Diseases of Humans. New York: Oxford University Press.

Angrist, J., G.W. Imbens, and D. Rubin. (1996). "Identification of Causal Effects using Instrumental Variables," Journal of the American Statistical Association, 91(434), 444-472.

Angrist, Joshua D., and Victor Lavy. (1999). "Using Maimonides' Rule to Estimate the Effect of Class Size on Scholastic Achievement," Quarterly Journal of Economics, 114(2), 533-575.

Behrman, Jere. (1996). "The Impact of Health and Nutrition on Education," World Bank Research Observer, 11(1), 23-37.

Bennett, Andrew, and Helen Guyatt. (2000). "Reducing Intestinal Nematode Infection: Efficacy of Albendazole and Mebendazole," Parasitology Today, 16 (2), 71-75.

Bloom, David, and Jeffrey Sachs. (1998). "Geography, Demography, and Economic Growth in Africa," Brookings Papers on Economic Activity, 2, 207-295.

Brinkley, Garland. (1994). "The Economic Impact of Disease in the American South, 1860-1940," Ph.D. dissertation, University of California at Davis.

Brooker, Simon, Megan Rowlands, Laurence Haller, Lorenzo Savioli, and Donald Bundy. (2000a). "Towards an atlas of helminth infection in sub-Saharan Africa: the use of geographical information systems (GIS)," Parasitology Today, 16(7), 303-307.

Brooker, S., Miguel, E.A., Moulin, S., Luoba, A.I., Bundy, D.A.P. \& Kremer, M. (2000b).

"Epidemiology of single and multiple species helminth infections among schoolchildren in Busia district, Kenya," East African Medical Journal 77, 157-161.

Brooker, S., Miguel, E.A., Moulin, S., Waswa, P., Namunyu, R., Guyatt, H. \& Bundy, D.A.P. (2001). "The potential of rapid screening methods for Schistosoma mansoni in Western Kenya," forthcoming Annals of Tropical Medicine and Parasitology.

Bundy, D.A.P. (1988). "Population ecology of intestinal helminth infections in human communities." Philosophical Transactions of the Royal Society of London. Series B. 321 (1207), 405-420.

Bundy, D.A.P. (1994). "The global burden of intestinal nematode disease." Transactions of the Royal Society of Tropical Medicine and Hygiene, 88, 259-261.

Bundy, D. A. P., Chan M.S., Medley, G.F., Jamison, D. \& Savioli, L. (2001). "Intestinal Nematode Infections." The global epidemiology of infectious diseases, (C. J. L. Murray and A. D. Lopez, eds). Cambridge: Harvard University Press.

Bundy, D.A.P., and E.S. Cooper. (1989). "Trichuris," in Tropical and Geographical Medicine, ed. K.S. Warren and A.A.F. Mahmoud. New York: McGraw-Hill. 
Bundy, D.A.P., and Guyatt, H.L. (1996). "Schools for Health: Focus on Health, Education, and the School-age Child." Parasitology Today, 12 (8), 1-16.

Bundy, D.A.P., Wong, M.S., Lewis, L.L., and Horton, J. (1990). "Control of geohelminths by delivery of targeted chemotherapy through schools." Transactions of the Royal Society of Tropical Medicine and Hygiene, 84, 115-120.

Bundy, D.A.P., Chan, M-S., Medley, G.F., Jamison, D., and Savioli, L. (1998). "Intestinal Nematode Infections." In Health Priorities and Burden of Disease Analysis: Methods and Applications from Global, National and Sub-national Studies. Harvard University Press for the World Health Organization and the World Bank (in press).

Colony and Protectorate of Kenya. (1928). Native Affairs Department Annual Report 1927. Nairobi: Government Press.

Corbett, E.L., Butterworth, A.E., Fulford, A.J.C., Ouma, J.H., Sturock, R.F. (1992). "Nutritional status of children with schistosomiasis mansoni in two different areas of Machakos District, Kenya." Transactions of the Royal Society of Tropical Medicine and Hygiene, 86, 266-273.

Cowden, John, and Peter Hotez. (2000). "Mebendazole and albendazole treatment of geohelminth infections in children and pregnant women," The Pediatric Infectious Disease Journal, 19(7), 659-660.

Das Gupta, Partha. (1993). An Inquiry into Well-Being and Destitution. Oxford: Clarendon Press.

Dickson, Rumona, Shally Awasthi, Paula Williamson, Colin Demellweek, and Paul Garner. (2000). "Effect of treatment for intestinal helminth infection on growth and cognitive performance in children: systematic review of randomized trials," British Medical Journal, 320 (June 24), 1697-1701.

Drake, L.J., M.C.H. Jukes, R.J. Sternberg, D.A.P. Bundy. (1999). "Geohelminthiasis (Ascariasis, Trichuriasis and hookworm): Cognitive and Developmental Impact," Seminars in Pediatric Infectious Disease, 11, 1-9.

Fogel, Robert. (1994). "Economic Growth, Population Theory and Physiology: The Bearing of LongTerm Processes on the Making of Economic Policy," American Economic Review, 84(3), 369-395.

Geissler, P.W. (1998a). "'Worms are our life', part I: understandings of worms and the body among the Luo of western Kenya", Anthropology and Medicine, 5(1), 63-79.

Geissler, P.W. (1998b). "'Worms are our life', part II: Luo children's thoughts about worms and illness", Anthropology and Medicine, 5(2), 133-144.

Geissler, P.W., Mwaniki, D.L., Thiong’o, F., Michaelsen, K.F., Friis, H. (1998). “Geophagy, Iron Status, and Anaemia among Primary School Children in Western Kenya," Tropical Medicine and International Health, 3 (7), 529-534.

Geissler, P. W., K. Nokes, R. J. Prince, R. Achieng' Odhiambo, J. Ochieng' Maende, J. Aagaard-Hansen. (2000). "Children and medicines: Self-treatment of common illnesses among Luo school children in Western Kenya," Social Science and Medicine, 50(18), 1771-1783. 
Glewwe, Paul, Michael Kremer, and Sylvie Moulin. (1999). “Textbooks and Test Scores,” mimeo., Harvard University and World Bank.

Hall, Andrew, and the Partnership for Child Development. (2000). "Anaemia in schoolchildren in eight countries in Africa and Asia," mimeo., Oxford University.

Heckman, James, and Jeffrey Smith. (1995). “Assessing the Case for Social Experiments," Journal of Economic Perspectives, 9(2), 85-110.

Heckman, James, Hidehiko Ichimura, Jeffrey Smith, and Petra Todd. (1998). "Characterizing Selection Bias Using Experimental Data," Econometrica, 66(5), 1017-1098.

Hotez, P.J., and Pritchard, D.I. (1995). "Hookworm Infection.” Scientific American, June, 68-74.

Knight, J.B., and Sabot, R.H. (1990). Education, Productivity, and Inequality. Oxford University Press: Washington D.C.

Medley, G., and R.M. Anderson. (1985). "Density-dependent fecundity in Schistosoma mansoni infections in man," Transactions of the Royal Society of Tropical Medicine and Hygiene, 79, 532-534.

Miguel, Edward, and Michael Kremer. (2001). "Social Networks and Learning About Health," mimeo., University of California at Berkeley.

Nokes, C., Grantham-McGregor, S.M., Sawyer, A.W., Cooper, E.S., Robinson, B.A., and Bundy, D.A.P. (1992). "Moderate-to-heavy infection of Trichuris trichiura affect cognitive function in Jamaican school children." Parasitology, 104, 539-547.

Nokes, C., van den Bosch, C., and Bundy, D.A.P. (1998). The Effects of Iron Deficiency and Anemia on Mental and Motor Performance, Educational Achievement, and Behavior in Children: A Report of the International Nutritional Anemia Consultative Group. USAID: Washington, DC.

Pollitt, E. (1990). "Infection: Schistosomiasis", Malnutrition and Infection in the Classroom, Paris, Unesco: 151-162.

Pollitt, E., Perez-Escamilla, R., Wayne, W., Latham, M.C., and Stephenson, L.S. (1991). "Effects of infection with Trichuris trichiura, Ascaris lumbricoides and hookworm on information processing among Kenyan school children." FASEB Journal, 5, A1081.

Simeon, D.T., Grantham-McGregor, S.M., and Wong, M.S. (1995). "Trichuris trichiura infection and cognition in children: results of a randomized clinical trial." Parasitology, 110, 457-464.

Simeon, D.T., Grantham-McGregor, S.M., Callender, J.E., and Wong, M.S. (1995). "Treatment of Trichuris trichiura Infections Improves Growth, Spelling Scores and School Attendance in Some Children." The Journal of Nutrition, 125, 1875-1883.

Stoltzfus, R.J., Chwaya, H.M., Tielsch, J.M., Schulze, K.J., Albonico, M., and Savioli, L. (1997). "Epidemiology of iron deficiency anemia in Zanzibari schoolchildren: the importance of hookworms." American Journal of Clinical Nutrition, 65, 153-159.

Udry, Christopher. (1996). "Gender, Agricultural Productivity, and the Theory of the Household," Journal of Political Economy, 104(5), 1010-1046. 
Warren, K.S., Bundy, D.A.P., Anderson, R.M., Davis, A.R., Henderson, D.A, Jamison, D.T., Prescott, N. and Senft, A. (1993). "Helminth infections." In Disease Control Priorities in Developing Countries (ed. Jamison, D.T., Mosley, W.H., Measham, A.R. and Bobadilla, J.L.), 131-60. Oxford University Press.

Watkins, W.E., Cruz, J.R., and Pollitt, E. (1996a). "The effects of deworming on indicators of school performance in Guatemala." Transactions of the Royal Society of Tropical Medicine and Hygiene, 90, $156-161$.

Watkins, W.E., Cruz, J.R., and Pollitt, E. (1996b). "Whether deworming imrpoves or impairs information processing depends on intensity of Ascaris infection." mimeo, Yale-China Association, Hong Kong.

Watkins, W. E., and Pollitt, E. (1997). “'Stupidity or Worms': Do Intestinal Worms Impair Mental Performance?” Psychological Bulletin, 121 (2), 171-191.

World Bank. (1993). World Development Report. Oxford University Press. New York.

World Bank. (1999). World Development Indicators (www.worldbank.org).

World Health Organization. (1987). Prevention and Control of intestinal parasitic infections. Report of the WHO Scientific Group. WHO Technical Report Series: 749. WHO, Geneva.

World Health Organization. (1992). Model Describing Information. Drugs used in Parasitic Diseases. WHO, Geneva.

World Health Organization. (1993). The control of schistosomiasis. Second report of the WHO expert committee. (Technical Report Series 830). WHO, Geneva.

World Health Organization. (1999). The World Health Report 1999: Making a Difference. WHO, Geneva.

World Health Organization. (2000). The World Health Report 2000. WHO, Geneva. 
Table 1: Primary School Deworming Project (PSDP) timeline, 1997-1999

\begin{tabular}{|c|c|}
\hline Dates & Activity \\
\hline \multicolumn{2}{|l|}{1997} \\
\hline$\overline{\text { October }}$ & $\begin{array}{l}\text { Pilot Kenya Ministry of Health, Division of Vector } \\
\text { Borne Disease (DVBD) parasitological survey. Pilot ICS } \\
\text { Pupil Questionnaire }\end{array}$ \\
\hline \multicolumn{2}{|l|}{1998} \\
\hline \multirow[t]{3}{*}{$\overline{\text { January-March }}$} & Parent-teacher meetings in Group 1 schools \\
\hline & $\begin{array}{l}\text { Pupil Questionnaire administration in grades } 3 \text { to } 8 \text {, and } \\
\text { School Questionnaire administration in all schools }\end{array}$ \\
\hline & $\begin{array}{l}\text { DVBD parasitological survey for grades } 3 \text { to } 8 \text { in Group } \\
1 \text { schools }\end{array}$ \\
\hline January-May & $\begin{array}{l}\text { Heavy precipitation and widespread flooding associated } \\
\text { with the El Nino weather phenomenon }\end{array}$ \\
\hline March-April & $\begin{array}{l}\text { First round of } 1998 \text { medical treatment (with albendazole, } \\
\text { praziquantel) in Group } 1 \text { schools }\end{array}$ \\
\hline October-November & $\begin{array}{l}\text { ICS (NGO) examinations administered in grades } 3 \text { to } 8 \text { in } \\
\text { all schools }\end{array}$ \\
\hline November & $\begin{array}{l}\text { Second round of } 1998 \text { medical treatment (with } \\
\text { albendazole) in Group } 1 \text { schools }\end{array}$ \\
\hline \multicolumn{2}{|l|}{1999} \\
\hline \multirow[t]{3}{*}{ January-March } & Parent-teacher meetings in Group 1 and Group 2 schools \\
\hline & $\begin{array}{l}\text { Pupil Questionnaire administration in grades } 3 \text { to } 8 \text {, and } \\
\text { School Questionnaire administration in all schools }\end{array}$ \\
\hline & $\begin{array}{l}\text { DVBD parasitological and hemoglobin surveys for } \\
\text { grades } 3 \text { to } 8 \text { in Group } 1 \text { and Group } 2 \text { schools }\end{array}$ \\
\hline March-June & $\begin{array}{l}\text { First round of } 1999 \text { medical treatment (with albendazole, } \\
\text { praziquantel) in Group } 1 \text { and Group } 2 \text { schools }\end{array}$ \\
\hline May-July & $\begin{array}{l}\text { Deworming drug availability survey of local shops, } \\
\text { clinics, and pharmacies }\end{array}$ \\
\hline October & $\begin{array}{l}\text { ICS (NGO) examinations administered in grades } 3 \text { to } 8 \text { in } \\
\text { all schools }\end{array}$ \\
\hline October-November & $\begin{array}{l}\text { Second round of } 1999 \text { medical treatment (with } \\
\text { albendazole) in Group } 1 \text { and Group } 2 \text { schools }\end{array}$ \\
\hline
\end{tabular}


Table 2: 1998 Average pupil and school characteristics, pre-treatment ${ }^{46}$

\begin{tabular}{|c|c|c|c|c|c|}
\hline & $\begin{array}{l}\text { Group } 1 \\
\text { (25 schools) }\end{array}$ & $\begin{array}{l}\text { Group } 2 \\
\text { (25 schools) }\end{array}$ & $\begin{array}{l}\text { Group } 3 \\
\text { (25 schools) }\end{array}$ & $\begin{array}{l}\text { Group } 1- \\
\text { Group } 3\end{array}$ & $\begin{array}{l}\text { Group } 2- \\
\text { Group } 3\end{array}$ \\
\hline \multicolumn{6}{|l|}{ Preschool to Grade 8} \\
\hline Male & 0.53 & 0.51 & 0.52 & $\begin{array}{c}0.01 \\
(0.02)\end{array}$ & $\begin{array}{l}-0.01 \\
(0.02)\end{array}$ \\
\hline Proportion girls $<13$ years, and all boys & 0.89 & 0.89 & 0.88 & $\begin{array}{l}0.00 \\
(0.01)\end{array}$ & $\begin{array}{c}0.01 \\
(0.01)\end{array}$ \\
\hline Grade progression $[=$ Grade $-($ Age -6$)]$ & -2.1 & -1.9 & -2.1 & $\begin{array}{l}-0.0 \\
(0.1)\end{array}$ & $\begin{array}{c}0.1 \\
(0.1)\end{array}$ \\
\hline Year of birth & 1986.2 & 1986.5 & 1985.8 & $\begin{array}{l}0.4^{* * *} \\
(0.2)\end{array}$ & $\begin{array}{l}0.8^{* * *} \\
(0.2)\end{array}$ \\
\hline \multicolumn{6}{|l|}{ Grades 3 to 8} \\
\hline Access to latrine at home & 0.82 & 0.81 & 0.82 & $\begin{array}{c}0.00 \\
(0.03)\end{array}$ & $\begin{array}{c}-0.01 \\
(0.03)\end{array}$ \\
\hline Cement floor at home & 0.21 & 0.24 & 0.21 & $\begin{array}{l}-0.01 \\
(0.03)\end{array}$ & $\begin{array}{c}0.03 \\
(0.04)\end{array}$ \\
\hline Have livestock (cows, goats, pigs, sheep) at home & 0.66 & 0.67 & 0.66 & $\begin{array}{l}-0.00 \\
(0.03)\end{array}$ & $\begin{array}{c}0.01 \\
(0.03)\end{array}$ \\
\hline $\begin{array}{l}\text { Weight-for-age Z-score (low scores denote } \\
\text { undernutrition) }\end{array}$ & -1.39 & -1.40 & -1.44 & $\begin{array}{c}0.05 \\
(0.05)\end{array}$ & $\begin{array}{c}0.04 \\
(0.05)\end{array}$ \\
\hline Blood in stool (self-reported) & 0.26 & 0.22 & 0.19 & $\begin{array}{l}0.07^{* *} \\
(0.03)\end{array}$ & $\begin{array}{c}0.03 \\
(0.03)\end{array}$ \\
\hline Sick often (self-reported) & 0.10 & 0.10 & 0.08 & $\begin{array}{l}0.02^{* *} \\
(0.01)\end{array}$ & $\begin{array}{l}0.02^{* *} \\
(0.01)\end{array}$ \\
\hline Malaria/fever in past week (self-reported) & 0.37 & 0.38 & 0.40 & $\begin{array}{l}-0.03 \\
(0.03)\end{array}$ & $\begin{array}{l}-0.02 \\
(0.03)\end{array}$ \\
\hline Clean (observed by field workers) & 0.60 & 0.66 & 0.67 & $\begin{array}{l}-0.07^{* *} \\
(0.03)\end{array}$ & $\begin{array}{l}-0.01 \\
(0.03)\end{array}$ \\
\hline $\begin{array}{l}\text { School characteristics } \\
\text { District mock exam score 1996, grades 5-8 }\end{array}$ & -0.10 & 0.09 & 0.01 & $\begin{array}{c}-0.11 \\
(0.12)\end{array}$ & $\begin{array}{c}0.08 \\
(0.12)\end{array}$ \\
\hline Local school spending per pupil (1997), KSh${ }^{48}$ & 95.8 & 108.6 & 123.0 & $\begin{array}{l}-27.1 \\
(41.5)\end{array}$ & $\begin{array}{l}-14.3 \\
(42.4)\end{array}$ \\
\hline Distance to Lake Victoria & 10.0 & 9.9 & 9.5 & $\begin{array}{l}0.6 \\
(1.9)\end{array}$ & $\begin{array}{l}0.5 \\
(1.9)\end{array}$ \\
\hline $\begin{array}{l}\text { Total number of other primary schools located } \\
\text { within } 3 \mathrm{~km} \text { of the school }\end{array}$ & 3.4 & 4.1 & 3.4 & $\begin{array}{l}0.0 \\
(0.5)\end{array}$ & $\begin{array}{l}0.7 \\
(0.5)\end{array}$ \\
\hline Pupil population & 392.7 & 403.8 & 375.9 & $\begin{array}{c}16.8 \\
(57.6)\end{array}$ & $\begin{array}{c}27.9 \\
(57.6)\end{array}$ \\
\hline School latrines per pupil & 0.007 & 0.006 & 0.007 & $\begin{array}{c}0.001 \\
(0.001)\end{array}$ & $\begin{array}{l}-0.000 \\
(0.001)\end{array}$ \\
\hline Proportion moderate-heavy infections in zone & 0.37 & 0.37 & 0.36 & $\begin{array}{c}0.01 \\
(0.03)\end{array}$ & $\begin{array}{c}0.01 \\
(0.03)\end{array}$ \\
\hline
\end{tabular}

\footnotetext{
${ }^{46}$ The results are school averages weighted by pupil population. Standard errors in parentheses. Significantly different than zero at $99(* * *), 95(* *)$, and $90\left(^{*}\right)$ percent confidence. Data from the 1998 ICS Pupil Namelist, 1998 Pupil Questionnaire and 1998 School Questionnaire.

${ }^{47} 1996$ District mock exam scores have been normalized to be in units of individual level standard deviations, and so are comparable in units to the 1998 and 1999 ICS test scores.

${ }^{48}$ This excludes two outlier schools with greater than 1000 Kenyan Shillings per pupil; however, the difference across groups remains insignificantly different than zero when these schools are included. The exchange rate in 1997 was approximately 50 Kenya Shillings $=1$ USD.
} 
Table 3: January 1998 helminth infections, pre-treatment, Group 1 schools ${ }^{49}$

\begin{tabular}{|c|c|c|c|}
\hline & $\begin{array}{l}\text { Prevalence of } \\
\text { infection }\end{array}$ & $\begin{array}{c}\text { Prevalence of } \\
\text { moderate-heavy } \\
\text { infection }\end{array}$ & $\begin{array}{l}\text { Average infection } \\
\text { intensity, in } \\
\text { eggs per gram (s.e.) }\end{array}$ \\
\hline Hookworm & 0.77 & 0.15 & $\begin{array}{c}426 \\
(1055)\end{array}$ \\
\hline Roundworm & 0.42 & 0.16 & $\begin{array}{c}2337 \\
(5156)\end{array}$ \\
\hline Schistosomiasis, all schools & 0.22 & 0.07 & $\begin{array}{c}91 \\
(413)\end{array}$ \\
\hline $\begin{array}{l}\text { Schistosomiasis, schools }<5 \mathrm{~km} \\
\text { from Lake Victoria }\end{array}$ & 0.80 & 0.39 & $\begin{array}{l}487 \\
(879)\end{array}$ \\
\hline Whipworm & 0.55 & 0.10 & $\begin{array}{c}161 \\
(470)\end{array}$ \\
\hline At least one infection & 0.92 & 0.37 & - \\
\hline Born since 1985 & 0.92 & 0.40 & - \\
\hline Born before 1985 & 0.91 & 0.34 & - \\
\hline Female & 0.91 & 0.34 & - \\
\hline Male & 0.93 & 0.38 & - \\
\hline At least two infections & 0.31 & 0.10 & - \\
\hline At least three infections & 0.28 & 0.01 & - \\
\hline
\end{tabular}

${ }^{49}$ These are averages of individual-level data, as presented in Brooker, et al. (2000b); correcting for the oversampling of the (numerically smaller) upper grades does not substantially change the results. Standard errors in parentheses. Sample size: 1894 pupils. Fifteen pupils per standard in grades 3 to 8 for Group 1 schools were randomly sampled. The bottom two rows should be interpreted as the proportion with at least two or at least three moderate-to-heavy helminth infections, respectively.

The data were collected in January to March 1998 by the Kenya Ministry of Health, Division of Vector Borne Diseases (DVBD). The moderate infection thresholds for the various intestinal helminths are: $250 \mathrm{epg}$ for $S$. mansoni, and 5,000 epg for Roundworm, both the WHO standard, and 750 epg for Hookworm and 400 epg for Whipworm, both somewhat lower than the WHO standard. Refer to Brooker, et al. (2000b) for a discussion of this parasitological survey and the infection cut-offs. All cases of schistosomiasis are $S$. mansoni. 
Table 4: Proportion of pupils receiving deworming treatment in PSDP ${ }^{50}$

\begin{tabular}{|c|c|c|c|c|c|c|}
\hline & \multicolumn{2}{|c|}{ Group 1} & \multicolumn{2}{|c|}{ Group 2} & \multicolumn{2}{|c|}{ Group 3} \\
\hline & $\begin{array}{c}\text { Girls }<13 \\
\text { years, and } \\
\text { all boys }\end{array}$ & $\begin{array}{c}\text { Girls } \geq \\
13 \text { years }\end{array}$ & $\begin{array}{c}\text { Girls }<13 \\
\text { years, and } \\
\text { all boys }\end{array}$ & $\begin{array}{c}\text { Girls } \geq \\
13 \text { years }\end{array}$ & $\begin{array}{c}\text { Girls }<13 \\
\text { years, and } \\
\text { all boys }\end{array}$ & $\begin{array}{c}\text { Girls } \geq \\
13 \text { years }\end{array}$ \\
\hline & \multicolumn{2}{|c|}{ Treatment } & \multicolumn{2}{|c|}{ Comparison } & \multicolumn{2}{|c|}{ Comparison } \\
\hline $\begin{array}{l}\text { Any medical treatment in } 1998 \\
\text { (For grades } 1-8 \text { in early 1998) }\end{array}$ & 0.78 & 0.19 & 0 & 0 & 0 & 0 \\
\hline Round 1 (March-April 1998), Albendazole & 0.69 & 0.11 & 0 & 0 & 0 & 0 \\
\hline Round 1 (March-April 1998), Praziquantel & 0.64 & 0.34 & 0 & 0 & 0 & 0 \\
\hline \multirow[t]{2}{*}{ Round 2 (Oct.-Nov. 1998), Albendazole } & 0.56 & 0.07 & 0 & 0 & 0 & 0 \\
\hline & \multicolumn{2}{|c|}{ Treatment } & \multicolumn{2}{|c|}{ Treatment } & \multicolumn{2}{|c|}{ Comparison } \\
\hline $\begin{array}{l}\text { Any medical treatment in } 1999 \\
\text { (For grades } 1-7 \text { in early 1998) }\end{array}$ & 0.59 & 0.07 & 0.55 & 0.10 & 0.01 & 0 \\
\hline Round 1 (March-June 1999), Albendazole & 0.44 & 0.06 & 0.35 & 0.06 & 0.01 & 0 \\
\hline Round 1 (March-June 1999), Praziquantel & 0.47 & 0.06 & 0.38 & 0.06 & 0.01 & 0 \\
\hline Round 2 (Oct.-Nov. 1999), Albendazole & 0.53 & 0.06 & 0.51 & 0.08 & 0.01 & 0 \\
\hline
\end{tabular}

Table 5: Proportion of pupil transfers across schools

\begin{tabular}{|c|c|c|c|c|c|c|}
\hline \multirow[b]{2}{*}{$\begin{array}{l}\text { School in early } 1998 \\
\text { (pre-treatment) }\end{array}$} & \multicolumn{3}{|c|}{1998 transfer to a } & \multicolumn{3}{|c|}{1999 transfer to a } \\
\hline & $\begin{array}{l}\text { Group } 1 \\
\text { School }\end{array}$ & $\begin{array}{c}\text { Group } 2 \\
\text { School }\end{array}$ & $\begin{array}{c}\text { Group } 3 \\
\text { school }\end{array}$ & $\begin{array}{c}\text { Group 1 } \\
\text { school }\end{array}$ & $\begin{array}{c}\text { Group } 2 \\
\text { school }\end{array}$ & $\begin{array}{c}\text { Group } 3 \\
\text { school }\end{array}$ \\
\hline Group 1 & 0.005 & 0.007 & 0.007 & 0.032 & 0.026 & 0.027 \\
\hline Group 2 & 0.006 & 0.007 & 0.008 & 0.026 & 0.033 & 0.027 \\
\hline Group 3 & 0.010 & 0.010 & 0.006 & 0.022 & 0.036 & 0.022 \\
\hline Total transfers & 0.021 & 0.024 & 0.021 & 0.080 & 0.095 & 0.076 \\
\hline
\end{tabular}

\footnotetext{
${ }^{50}$ Data for grades 1-8. Since month and date of birth information is missing for most pupils, precise assignment of treatment eligibility status for girls born during the "threshold" year is often impossible; all girls who turn 13 during a given year are counted as 12 year olds (eligible for deworming treatment) for consistency.
} 
Table 6: The direct health impact of deworming, January to March 1999, Group 1 schools (1998 Treatment) versus Group 2 schools (1998 Comparison) ${ }^{51}$

\begin{tabular}{|c|c|c|c|}
\hline & Group 1 & Group 2 & $\begin{array}{l}\text { Group } 1- \\
\text { Group } 2\end{array}$ \\
\hline Any moderate-heavy infection, 1998 & 0.38 & - & - \\
\hline Any moderate-heavy infection, 1999 & 0.27 & 0.52 & $\begin{array}{c}-0.25^{* * *} \\
(0.06)\end{array}$ \\
\hline Hookworm moderate-heavy infection, 1999 & 0.06 & 0.22 & $\begin{array}{l}-0.16^{* * *} \\
(0.03)\end{array}$ \\
\hline Roundworm moderate-heavy infection, 1999 & 0.09 & 0.24 & $\begin{array}{l}-0.15^{* * *} \\
(0.04)\end{array}$ \\
\hline Schistosomiasis moderate-heavy infection, 1999 & 0.08 & 0.18 & $\begin{array}{l}-0.10^{*} \\
(0.06)\end{array}$ \\
\hline Whipworm moderate-heavy infection, 1999 & 0.13 & 0.17 & $\begin{array}{l}-0.04 \\
(0.05)\end{array}$ \\
\hline $\begin{array}{l}\text { Other Nutritional and Health Outcomes } \\
\text { Sick in past week (self-reported), } 1999\end{array}$ & 0.41 & 0.45 & $\begin{array}{l}-0.04^{* *} \\
(0.02)\end{array}$ \\
\hline Sick often (self-reported), 1999 & 0.12 & 0.15 & $\begin{array}{l}-0.03^{* *} \\
(0.01)\end{array}$ \\
\hline $\begin{array}{l}\text { Height-for-age Z-score, } 1999 \\
\text { (low scores denote undernutrition) }\end{array}$ & -1.13 & -1.22 & $\begin{array}{l}0.09^{*} \\
(0.05)\end{array}$ \\
\hline $\begin{array}{l}\text { Weight-for-age Z-score, } 1999 \\
\text { (low scores denote undernutrition) }\end{array}$ & -1.25 & -1.25 & $\begin{array}{l}-0.00 \\
(0.04)\end{array}$ \\
\hline Hemoglobin concentration (g/L), 1999 & 124.8 & 123.2 & $\begin{array}{c}1.6 \\
(1.4)\end{array}$ \\
\hline Proportion anemic $(\mathrm{Hb}<100 \mathrm{~g} / \mathrm{L}), 1999$ & 0.02 & 0.04 & $\begin{array}{l}-0.02^{* *} \\
(0.01)\end{array}$ \\
\hline $\begin{array}{l}\text { Worm Prevention Behaviors } \\
\text { Clean (observed by field worker), } 1999\end{array}$ & 0.59 & 0.60 & $\begin{array}{l}-0.01 \\
(0.02)\end{array}$ \\
\hline Wears shoes (observed by field worker), 1999 & 0.24 & 0.26 & $\begin{array}{l}-0.02 \\
(0.03)\end{array}$ \\
\hline $\begin{array}{l}\text { Days contact with fresh water in past week } \\
\text { (self-reported), } 1999\end{array}$ & 2.4 & 2.2 & $\begin{array}{c}0.2 \\
(0.3)\end{array}$ \\
\hline
\end{tabular}

51 These are averages of individual-level data for grade 3-8 pupils; disturbance terms are clustered within schools. Robust standard errors in parentheses. Significantly different than zero at $99(* * *), 95(* *)$, and $90(*)$ percent confidence.

Obs. for parasitological results: 2153 (609 Group 1, 1544 Group 2).

Obs. for hemoglobin results: 778 (292 Group 1, 486 Group 2).

Obs. for 1999 Pupil Questionnaire health outcomes: 9,102 (3562 Group 1, 5540 Group 2 and Group 3).

The moderate-to-heavy infection thresholds for the various intestinal helminths are: 250 epg for S. mansoni, and 5,000 epg for Roundworm, both the WHO standard, and 750 epg for Hookworm and 400 epg for Whipworm, both somewhat lower than the WHO standard. Refer to Brooker, et al (2000b) for a discussion of this parasitological survey and the infection cut-offs. Kenya Ministry of Health officials collected the parasitological data from January to March 1998 in Group 1 schools, and from January to March 1999 in Group 1 and Group 2 schools. A random subset of the original 1998 Group 1 parasitological sample was re-surveyed in 1999. Hb data were collected by Kenya Ministry of Health officials and ICS field officers using the portable Hemocue machine. The self-reported health outcomes were collected for all three groups of schools as part of Pupil Questionnaire administration. 
Table 7: Deworming health externalities within schools, January to March $1999^{52}$

\begin{tabular}{|c|c|c|c|c|c|c|}
\hline & $\begin{array}{l}\text { Group 1, } \\
\text { Treated } \\
\text { in } 1998\end{array}$ & $\begin{array}{c}\text { Group 1, } \\
\text { Untreated } \\
\text { in } 1998\end{array}$ & $\begin{array}{c}\text { Group 2, } \\
\text { Treated in } \\
1999\end{array}$ & $\begin{array}{c}\text { Group 2, } \\
\text { Untreated } \\
\text { in } 1999\end{array}$ & $\begin{array}{c}\text { (Group 1 } \\
\text { Treated } \\
\text { 1998) - } \\
\text { (Group 2, } \\
\text { Treated } \\
\text { 1999) } \\
\end{array}$ & $\begin{array}{c}\text { (Group 1, } \\
\text { Untreated } \\
\text { 1998) - } \\
\text { (Group 2, } \\
\text { Untreated } \\
1999 \text { ) }\end{array}$ \\
\hline $\begin{array}{l}\text { Girls }<13 \text { years, and all boys } \\
\text { Any moderate-heavy infection, } 1999\end{array}$ & 0.24 & 0.34 & 0.51 & 0.55 & $\begin{array}{c}-0.27^{* * *} \\
(0.06)\end{array}$ & $\begin{array}{c}-0.21^{* *} \\
(0.10)\end{array}$ \\
\hline $\begin{array}{l}\text { Hookworm moderate-heavy } \\
\text { infection, } 1999\end{array}$ & 0.04 & 0.11 & 0.22 & 0.20 & $\begin{array}{l}-0.19^{* * *} \\
(0.03)\end{array}$ & $\begin{array}{l}-0.09^{*} \\
(0.05)\end{array}$ \\
\hline $\begin{array}{l}\text { Roundworm moderate-heavy } \\
\text { infection, } 1999\end{array}$ & 0.08 & 0.12 & 0.22 & 0.30 & $\begin{array}{c}-0.14^{* * *} \\
(0.04)\end{array}$ & $\begin{array}{l}-0.18^{* *} \\
(0.07)\end{array}$ \\
\hline $\begin{array}{l}\text { Schistosomiasis moderate-heavy } \\
\text { infection, } 1999\end{array}$ & 0.09 & 0.08 & 0.20 & 0.13 & $\begin{array}{l}-0.11^{*} \\
(0.06)\end{array}$ & $\begin{array}{l}-0.05 \\
(0.06)\end{array}$ \\
\hline $\begin{array}{l}\text { Whipworm moderate-heavy } \\
\text { infection, } 1999\end{array}$ & 0.12 & 0.16 & 0.16 & 0.20 & $\begin{array}{l}-0.04 \\
(0.16)\end{array}$ & $\begin{array}{l}-0.05 \\
(0.09)\end{array}$ \\
\hline $\begin{array}{l}\text { Proportion of } 1998 \text { parasitological } \\
\text { sample tracked to } 1999 \text { sample }^{53}\end{array}$ & 0.36 & 0.36 & - & - & - & - \\
\hline Any moderate-heavy infection, 1998 & 0.39 & 0.41 & - & - & - & - \\
\hline Access to latrine at home, 1998 & 0.84 & 0.80 & 0.81 & 0.86 & $\begin{array}{c}0.03 \\
(0.04)\end{array}$ & $\begin{array}{l}-0.06 \\
(0.05)\end{array}$ \\
\hline $\begin{array}{l}\text { Grade progression }[=\text { Grade }-(\text { Age }- \\
6)], 1998\end{array}$ & -2.0 & -1.8 & -1.8 & -1.8 & $\begin{array}{l}-0.2^{* *} \\
(0.1)\end{array}$ & $\begin{array}{l}-0.0 \\
(0.2)\end{array}$ \\
\hline $\begin{array}{l}\text { Weight-for-age (Z-score), } 1998 \\
\text { (low scores denote undernutrition) }\end{array}$ & -1.58 & -1.52 & -1.57 & -1.46 & $\begin{array}{l}-0.01 \\
(0.06)\end{array}$ & $\begin{array}{l}-0.06 \\
(0.11)\end{array}$ \\
\hline $\begin{array}{l}\text { Malaria/fever in past week (self- } \\
\text { reported), } 1998\end{array}$ & 0.37 & 0.41 & 0.40 & 0.39 & $\begin{array}{l}-0.03 \\
(0.04)\end{array}$ & $\begin{array}{l}-0.01 \\
(0.06)\end{array}$ \\
\hline $\begin{array}{l}\text { Clean (observed by field worker), } \\
1998\end{array}$ & 0.53 & 0.59 & 0.60 & 0.66 & $\begin{array}{l}-0.07 \\
(0.05)\end{array}$ & $\begin{array}{l}-0.07 \\
(0.10)\end{array}$ \\
\hline
\end{tabular}

${ }^{52}$ These are averages of individual-level data for grade 3-8 pupils in the parasitological survey subsample; disturbance terms are clustered within schools. Robust standard errors in parentheses. Significantly different than zero at $99(* * *), 95(* *)$, and $90(*)$ percent confidence. The data are described in the footnote to Table 6 .

${ }^{53}$ We attempted to track a random sample of half of the original 1998 parasitological sample. Because some pupils were absent, had dropped out, or had graduated, we were only able to re-survey $72 \%$ of this subsample.

Obs. for parasitological survey: 670 Group 1 treated 1998, 77 Group 1 untreated 1998, 873 Group 2 treated 1999, 352 Group 2 untreated 1999. 
Table 8: Deworming health externalities across schools, January to March $1999^{54}$

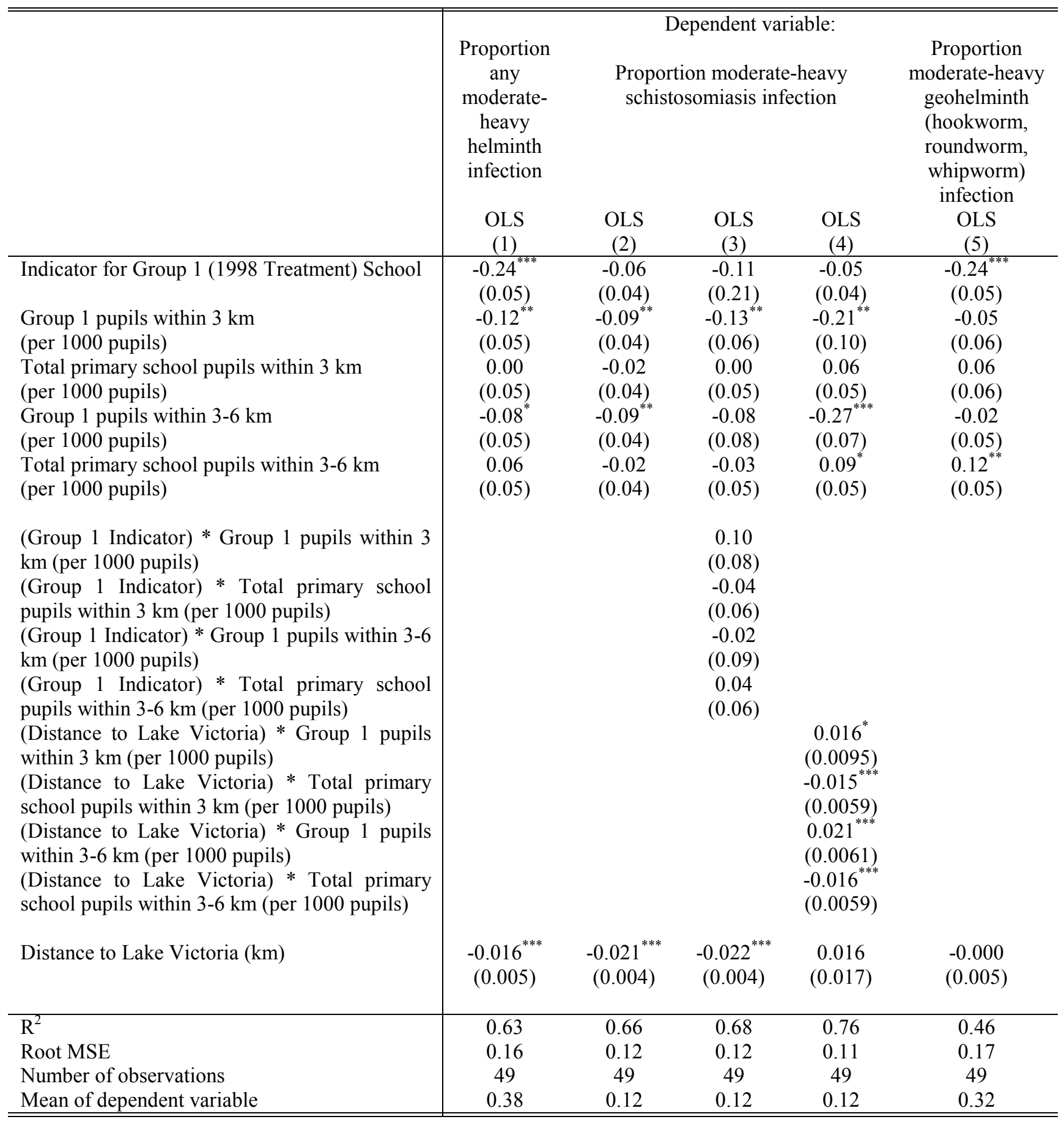

${ }^{54}$ The dependent variables are school-level averages, for grade 3-8 pupils. Robust standard errors in parentheses. Significantly different than zero at $99(* * *), 95(* *)$, and $90(*)$ percent confidence. The 1999 parasitological survey data are for Group 1 and Group 2 schools. The pupil population data is from the 1998 School Questionnaire. The means (standard errors) of the population variables: Group 1 pupils within $3 \mathrm{~km}, 449$ (461); Total pupils within 3 km, 1448 (789); Group 1 pupils within 3-6 km, 791 (538); Total pupils within 3-6 km, 2385 (834). 
Table 9: School participation, school-level data ${ }^{55}$

\begin{tabular}{|c|c|c|c|c|c|}
\hline & $\begin{array}{c}\text { Group 1 } \\
(25 \text { schools })\end{array}$ & $\begin{array}{c}\text { Group } 2 \\
(25 \text { schools })\end{array}$ & $\begin{array}{c}\text { Group } 3 \\
(25 \text { schools }) \\
\end{array}$ & & \\
\hline $\begin{array}{l}\text { First year post-treatment } \\
\text { (May } 1998 \text { to March 1999) }\end{array}$ & $\begin{array}{l}1^{\text {st }} \text { Year } \\
\text { Treatment }\end{array}$ & Comparison & Comparison & $\begin{array}{c}\text { Group } 1- \\
\text { (Group } 2 \& \\
\text { Group 3) }\end{array}$ & $\begin{array}{l}\text { Group } 2- \\
\text { Group } 3\end{array}$ \\
\hline Girls $<13$ years, and all boys & 0.841 & 0.731 & 0.767 & $\begin{array}{l}0.093^{* * *} \\
(0.031)\end{array}$ & $\begin{array}{l}-0.037 \\
(0.036)\end{array}$ \\
\hline Girls $\geq 13$ years & 0.864 & 0.803 & 0.811 & $\begin{array}{l}0.057^{* *} \\
(0.029)\end{array}$ & $\begin{array}{l}-0.008 \\
(0.034)\end{array}$ \\
\hline Preschool, Grade 1, Grade 2 in early 1998 & 0.795 & 0.688 & 0.703 & $\begin{array}{l}0.100^{* * * *} \\
(0.037)\end{array}$ & $\begin{array}{l}-0.018 \\
(0.043)\end{array}$ \\
\hline Grade 3, Grade 4, Grade 5 in early 1998 & 0.880 & 0.789 & 0.831 & $\begin{array}{l}0.070^{* * * *} \\
(0.024)\end{array}$ & $\begin{array}{l}-0.043 \\
(0.029)\end{array}$ \\
\hline Grade 6, Grade 7, Grade 8 in early 1998 & 0.934 & 0.858 & 0.892 & $\begin{array}{l}0.059^{* * * *} \\
(0.021)\end{array}$ & $\begin{array}{l}-0.034 \\
(0.026)\end{array}$ \\
\hline Recorded as "dropped out" in early 1998 & 0.064 & 0.050 & 0.030 & $\begin{array}{c}0.022 \\
(0.018)\end{array}$ & $\begin{array}{c}0.020 \\
(0.017)\end{array}$ \\
\hline Females $^{56}$ & 0.855 & 0.771 & 0.789 & $\begin{array}{l}0.076^{* * *} \\
(0.027)\end{array}$ & $\begin{array}{l}-0.018 \\
(0.032)\end{array}$ \\
\hline Males & 0.844 & 0.736 & 0.780 & $\begin{array}{l}0.088^{* * *} \\
(0.031)\end{array}$ & $\begin{array}{l}-0.044 \\
(0.037)\end{array}$ \\
\hline $\begin{array}{l}\text { Second year post-treatment } \\
\text { (March to November 1999) }\end{array}$ & $\begin{array}{l}2^{\text {nd }} \text { Year } \\
\text { Treatment }\end{array}$ & $\begin{array}{c}1^{\text {st }} \text { Year } \\
\text { Treatment }\end{array}$ & Comparison & $\begin{array}{l}\text { Group } 1- \\
\text { Group } 3\end{array}$ & $\begin{array}{l}\text { Group } 2- \\
\text { Group } 3\end{array}$ \\
\hline Girls $<13$ years, and all boys & 0.713 & 0.717 & 0.663 & $\begin{array}{l}0.050^{*} \\
(0.028)\end{array}$ & $\begin{array}{c}0.055^{*} \\
(0.028)\end{array}$ \\
\hline Girls $\geq 14$ years $^{57}$ & 0.627 & 0.649 & 0.588 & $\begin{array}{c}0.039 \\
(0.035)\end{array}$ & $\begin{array}{l}0.061^{*} \\
(0.035)\end{array}$ \\
\hline Preschool, Grade 1, Grade 2 in early 1998 & 0.692 & 0.726 & 0.641 & $\begin{array}{c}0.051 \\
(0.034)\end{array}$ & $\begin{array}{l}0.085^{* *} \\
(0.034)\end{array}$ \\
\hline Grade 3, Grade 4, Grade 5 in early 1998 & 0.750 & 0.774 & 0.725 & $\begin{array}{l}0.025 \\
(0.023)\end{array}$ & $\begin{array}{l}0.049^{* *} \\
(0.023)\end{array}$ \\
\hline Grade 6, Grade 7, Grade 8 in early 1998 & 0.770 & 0.777 & 0.751 & $\begin{array}{l}0.020 \\
(0.027)\end{array}$ & $\begin{array}{c}0.026 \\
(0.028)\end{array}$ \\
\hline Recorded as "dropped out" in early 1998 & 0.176 & 0.129 & 0.056 & $\begin{array}{l}0.120^{*} \\
(0.063)\end{array}$ & $\begin{array}{c}0.073 \\
(0.053)\end{array}$ \\
\hline Females & 0.716 & 0.746 & 0.648 & $\begin{array}{l}0.067^{* *} \\
(0.027)\end{array}$ & $\begin{array}{l}0.098^{* * *} \\
(0.027)\end{array}$ \\
\hline Males & 0.698 & 0.695 & 0.655 & $\begin{array}{c}0.043 \\
(0.028)\end{array}$ & $\begin{array}{c}0.041 \\
(0.029)\end{array}$ \\
\hline
\end{tabular}

${ }^{55}$ The results are school averages weighted by pupil population. Standard errors in parentheses. Significantly different than zero at $99(* * *), 95(* *)$, and $90\left(^{*}\right)$ percent confidence. The participation rate is computed among all pupils enrolled in the school at the start of 1998. Pupils who are present in school on the day of an unannounced NGO visit are considered participants. Pupils had 3.8 participation observations per year on average. The figures for the "Preschool-Grade 2"; "Grade 3-5"; "Grade 6-8"; and "Dropout" rows are for girls < 13 years, and all boys. ${ }^{56} 396$ pupils in the sample are missing information on gender. For this reason, the average of the female and male participation rates does not equal the overall average.

${ }^{57}$ Examining girls $\geq 14$ years old eliminates the cohort of girls in Group 1 schools (12 year olds in 1998) who received deworming treatment in 1998. 
Table 10: School participation externalities within schools, May 1998 to March $1999^{58}$

\begin{tabular}{|c|c|c|c|c|c|c|}
\hline & $\begin{array}{l}\text { Group 1, } \\
\text { Treated } \\
\text { in } 1998\end{array}$ & $\begin{array}{l}\text { Group 1, } \\
\text { Untreated } \\
\text { in } 1998\end{array}$ & $\begin{array}{l}\text { Group 2, } \\
\text { Treated in } \\
1999\end{array}$ & $\begin{array}{l}\text { Group 2, } \\
\text { Untreated } \\
\text { in } 1999\end{array}$ & $\begin{array}{c}\text { (Group 1, } \\
\text { Treated 1998) } \\
-(\text { Group 2, } \\
\text { Treated 1999) }\end{array}$ & $\begin{array}{c}\text { (Group 1, } \\
\text { Untreated 1998) } \\
-(\text { Group 2, } \\
\text { Untreated 1999) }\end{array}$ \\
\hline $\begin{array}{l}\text { Girls }<13 \text { years, and all } \\
\text { boys (excludes grade } 8 \text { and } \\
\text { pupils who were } \\
\text { "dropouts" in early 1998) }\end{array}$ & \multicolumn{2}{|c|}{$1^{\text {st }}$ Year Treatment } & \multicolumn{2}{|c|}{ Comparison } & & \\
\hline $\begin{array}{l}\text { School participation rate, } \\
\text { May } 1998 \text { to March } 1999\end{array}$ & 0.872 & 0.764 & 0.808 & 0.684 & $\begin{array}{l}0.064^{* *} \\
(0.032)\end{array}$ & $\begin{array}{l}0.080^{* *} \\
(0.039)\end{array}$ \\
\hline $\begin{array}{l}\text { Access to latrine at home, } \\
1998\end{array}$ & 0.82 & 0.80 & 0.81 & 0.81 & $\begin{array}{c}0.01 \\
(0.03)\end{array}$ & $\begin{array}{l}-0.00 \\
(0.04)\end{array}$ \\
\hline $\begin{array}{l}\text { Grade progression, Grade - } \\
(\text { Age }-6), 1998\end{array}$ & -1.9 & -1.9 & -1.7 & -1.9 & $\begin{array}{l}-0.2^{* *} \\
(0.1)\end{array}$ & $\begin{array}{c}0.1 \\
(0.1)\end{array}$ \\
\hline $\begin{array}{l}\text { Weight-for-age (Z-score), } \\
1998 \text { (low scores denote } \\
\text { undernutrition) }\end{array}$ & -1.53 & -1.39 & -1.51 & -1.53 & $\begin{array}{l}-0.02 \\
(0.05)\end{array}$ & $\begin{array}{l}0.14^{* *} \\
(0.07)\end{array}$ \\
\hline $\begin{array}{l}\text { Malaria/fever in past week } \\
\text { (self-reported), } 1998\end{array}$ & 0.37 & 0.34 & 0.38 & 0.40 & $\begin{array}{l}-0.01 \\
(0.03)\end{array}$ & $\begin{array}{l}-0.06 \\
(0.04)\end{array}$ \\
\hline $\begin{array}{l}\text { Clean (observed by field } \\
\text { worker), } 1998\end{array}$ & 0.54 & 0.57 & 0.59 & 0.58 & $\begin{array}{l}-0.05 \\
(0.04)\end{array}$ & $\begin{array}{l}-0.01 \\
(0.05)\end{array}$ \\
\hline
\end{tabular}

\footnotetext{
${ }^{58}$ The results are school averages weighted by pupil population. Standard errors in parentheses. Significantly different than zero at $99(* * *), 95(* *)$, and $90(*)$ percent confidence. The participation rate is computed among pupils enrolled in the school at the start of 1998. Pupils who are present in school on the day of an unannounced NGO visit are considered participants. Pupils had 3.8 participation observations per year on average. School participation rates are for grades 1 to 7; grade 8 pupils are excluded since many graduated after the 1998 school year, in which case their actual 1999 treatment status is not relevant. Preschool pupils are excluded since they typically have missing compliance data. All 1998 pupil characteristics (access to latrine, weight-for-age, etc.) are for grades 3 to 7, since grade 1-2 pupils were not administered the Pupil Questionnaire.
} 
Table 11: School participation, individual-level data ${ }^{59}$

\begin{tabular}{|c|c|c|c|c|}
\hline & \multicolumn{4}{|c|}{$\begin{array}{c}\text { Dependent variable: } \\
\text { Average individual school participation, by year }\end{array}$} \\
\hline & $\begin{array}{l}\text { OLS } \\
(1)\end{array}$ & $\begin{array}{l}\text { OLS } \\
(2)\end{array}$ & $\begin{array}{l}\text { OLS } \\
\text { (3) }\end{array}$ & $\begin{array}{c}\text { OLS } \\
(4) \\
\text { May 98- } \\
\text { March 99 }\end{array}$ \\
\hline Treatment school $(\mathrm{T})$ & $\begin{array}{l}0.056^{* * *} \\
(0.014)\end{array}$ & & & \\
\hline First year as treatment school (T1) & & $\begin{array}{l}0.062^{* * *} \\
(0.015)\end{array}$ & $\begin{array}{c}0.063^{* * *} \\
(0.015)\end{array}$ & \\
\hline Second year as treatment school (T2) & & $\begin{array}{l}0.040^{*} \\
(0.021)\end{array}$ & $\begin{array}{l}0.037^{*} \\
(0.021)\end{array}$ & \\
\hline Moderate-heavy infection, early 1999 & & & & $\begin{array}{c}-0.028^{* * *} \\
(0.010)\end{array}$ \\
\hline $\begin{array}{l}1996 \text { District Mock exam score, } \\
\text { school average }\end{array}$ & $\begin{array}{l}0.072^{* * *} \\
(0.020)\end{array}$ & $\begin{array}{c}0.071^{* * *} \\
(0.020)\end{array}$ & $\begin{array}{c}0.070^{* * *} \\
(0.020)\end{array}$ & $\begin{array}{c}0.013 \\
(0.023)\end{array}$ \\
\hline $\begin{array}{l}\text { Treatment school pupils within } 3 \mathrm{~km} \\
\text { (per } 1000 \text { pupils) }\end{array}$ & & & $\begin{array}{l}0.034^{*} \\
(0.019)\end{array}$ & \\
\hline $\begin{array}{l}\text { Total primary school pupils within } 3 \mathrm{~km} \\
\text { (per } 1000 \text { pupils) }\end{array}$ & & & $\begin{array}{l}-0.020^{*} \\
(0.011)\end{array}$ & \\
\hline $\begin{array}{l}\text { Grade indicators, school assistance } \\
\text { controls, and time controls }\end{array}$ & & Yes & Yes & Yes \\
\hline $\mathrm{R}^{2}$ & 0.23 & 0.23 & 0.24 & 0.27 \\
\hline Root MSE & 0.272 & 0.272 & 0.272 & 0.151 \\
\hline Number of observations & 56442 & 56442 & 56442 & 2327 \\
\hline Mean of dependent variable & 0.747 & 0.747 & 0.747 & 0.884 \\
\hline
\end{tabular}

${ }^{59}$ The dependent variable is average individual school participation in each year of the program (Year 1 is May 1998 to March 1999, and Year 2 is May 1999 to November 1999); disturbance terms are clustered within schools. Robust standard errors in parentheses. Significantly different than zero at $99(* * *), 95(* *)$, and $90(*)$ percent confidence. Additional explanatory variables include an indicator variable for girls $<13$ years and all boys, and the rate of moderate-heavy infections in geographic zone, by grade (zonal infection rates among grade 3 and 4 pupils are used for pupils in grades 4 and below and for pupils initially recorded as dropouts as there is no parasitological data for pupils below grade 3; zonal infection rates among grade 5 and 6 pupils are used for pupils in grades 5 and 6 , and similarly for grades 7 and 8). Participation is computed among all pupils enrolled at the start of the 1998 school year. Pupils present during an unannounced NGO school visit are considered participants. Pupils had approximately 3.8 attendance observations per year. Regression 4 includes pupils with parasitological information from early 1999, restricting the sample to a random subset of Group 1 and Group 2 pupils. The average number of treatment school pupils within $3 \mathrm{~km}$ from May 1998 to March 1999 is the average number of Group 1 pupils (449.4); the average number of treatment school pupils within $3 \mathrm{~km}$ after March 1999 is the average number of Group 1 and Group 2 pupils (1020.9). 
Table 12: Academic examinations, individual-level data ${ }^{60}$

\begin{tabular}{|c|c|c|c|}
\hline & \multicolumn{3}{|c|}{$\begin{array}{c}\text { Dependent variable: ICS Exam Score } \\
\text { (normalized by standard) }\end{array}$} \\
\hline & (1) & (2) & $\begin{array}{l}\text { (3) } \\
\text { Filled in } 1998 \\
\text { survey }\end{array}$ \\
\hline $\begin{array}{l}\text { Average school participation (during the } \\
\text { year of the exam) }\end{array}$ & $\begin{array}{l}0.629^{* * *} \\
(0.068)\end{array}$ & & \\
\hline First year as treatment school (T1) & & $\begin{array}{l}-0.041 \\
(0.049)\end{array}$ & $\begin{array}{c}-0.042 \\
(0.053)\end{array}$ \\
\hline Second year as treatment school (T2) & & $\begin{array}{l}-0.045 \\
(0.074)\end{array}$ & $(0.083)$ \\
\hline $\begin{array}{l}1996 \text { District Mock exam score, } \\
\text { school average }\end{array}$ & $\begin{array}{l}0.736^{* * *} \\
(0.073)\end{array}$ & $\begin{array}{l}0.750^{* * *} \\
(0.070)\end{array}$ & $\begin{array}{l}0.781^{* * * *} \\
(0.071)\end{array}$ \\
\hline $\begin{array}{l}\text { Grade indicators, and } \\
\text { school assistance controls }\end{array}$ & Yes & Yes & Yes \\
\hline $\mathrm{R}^{2}$ & 0.14 & 0.13 & 0.14 \\
\hline Root MSE & 0.919 & 0.926 & 0.920 \\
\hline Number of observations & 25062 & 25062 & 19144 \\
\hline Mean of dependent variable & 0.020 & 0.020 & 0.037 \\
\hline
\end{tabular}

${ }^{60}$ Each data point is the individual-level exam result in a given year of the program (either 1998, or 1999); disturbance terms are clustered within schools. Robust standard errors in parentheses. Significantly different than zero at $99(* * *), 95(* *)$, and $90\left(^{*}\right)$ percent confidence. Regression 3 includes only pupils who completed the 1998 Pupil Questionnaire. Additional explanatory variables include an indicator variable for girls $<13$ years and all boys, and the rate of moderate-to-heavy infections in geographic zone, by grade (zonal infection rates among grade 3 and 4 pupils are used for pupils in grades 4 and below and for pupils initially recorded as dropouts as there is no parasitological data for pupils below grade 3; zonal infection rates among grade 5 and 6 pupils are used for pupils in grades 5 and 6 , and similarly for grades 7 and 8 ). 
Figure 1: Primary School Deworming Project Schools, Busia District, Kenya ${ }^{61}$

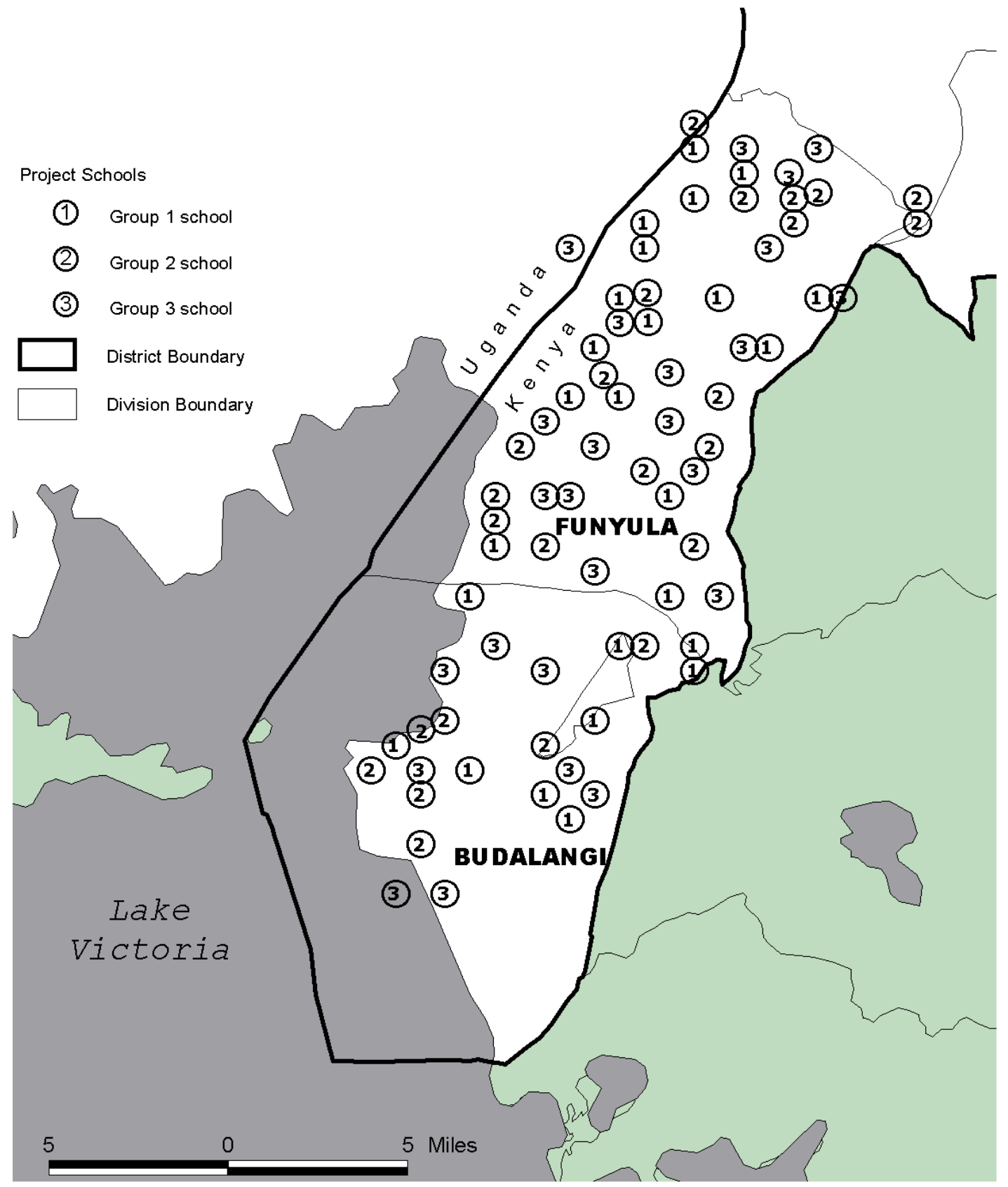

\footnotetext{
${ }^{61}$ The GPS locations were collected before May 2000 (when the U.S. stopped intentionally downgrading GPS accuracy), and so may only be accurate to within several hundred meters, thus one school in Figure 1 appears to be in Uganda. The school that appears to be in Lake Victoria is actually on a small island.
} 
Figure 2: School participation rate May 1998 to November 1999 for girls under 13 years old and for all boys, difference between Group 1 and Group 3 (diamonds), and difference between Group 2 and Group 3 (squares) ${ }^{62}$

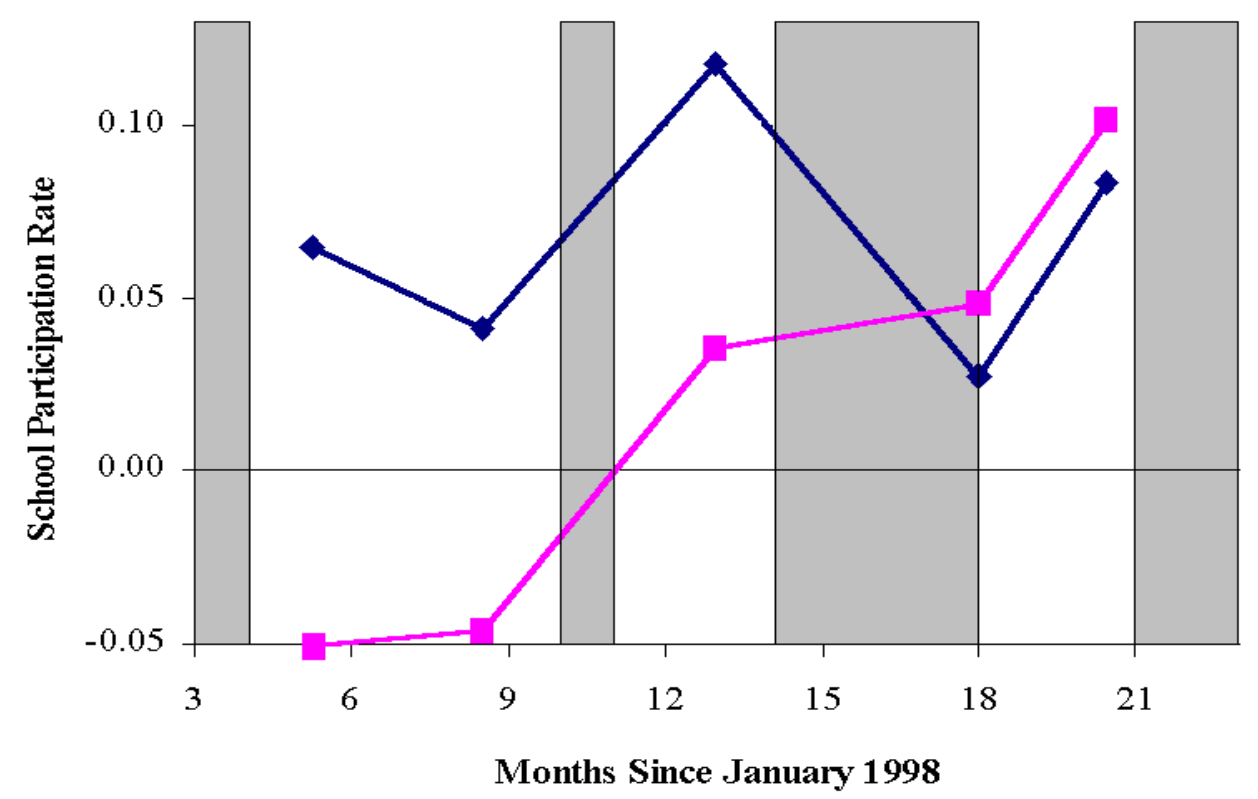

${ }^{62}$ The shaded regions are periods in which medical treatment was being provided--in March-April and November 1998 to Group 1 schools, and in March-June and October-November 1999 to Group 1 and Group 2 schools. 
Figure 3: Average school participation rate from May 1998 to November 1999 among girls less than 13 years old and all boys, histograms for Treatment (Group 1) schools and Comparison (Group 3) schools

Group $1 \square$ Group 3

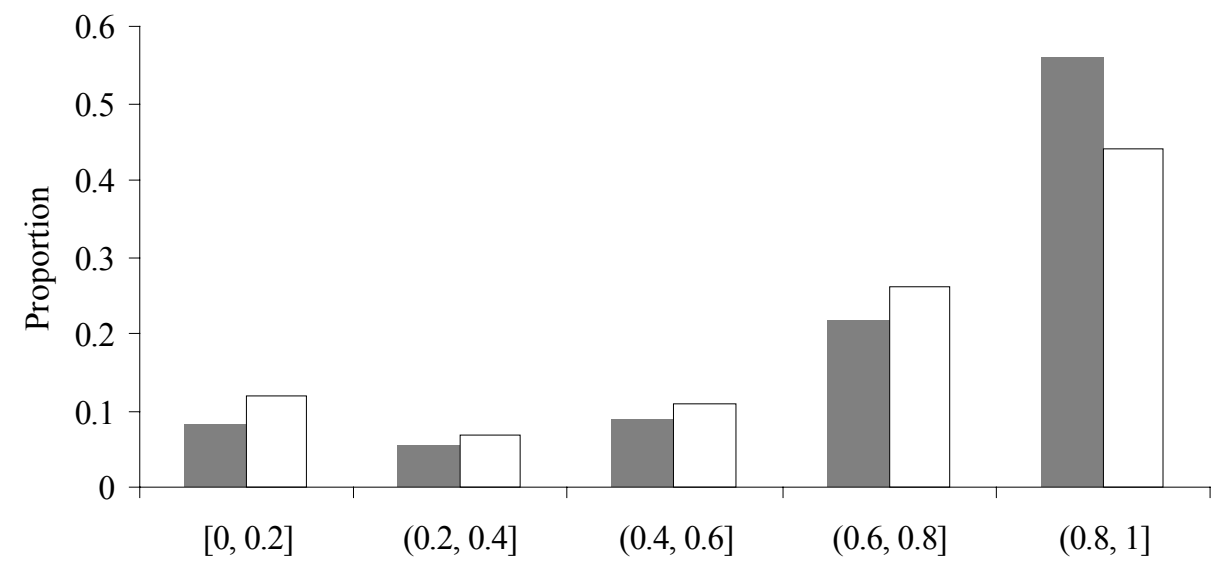

Average school participation, May 1998 to November 1999 